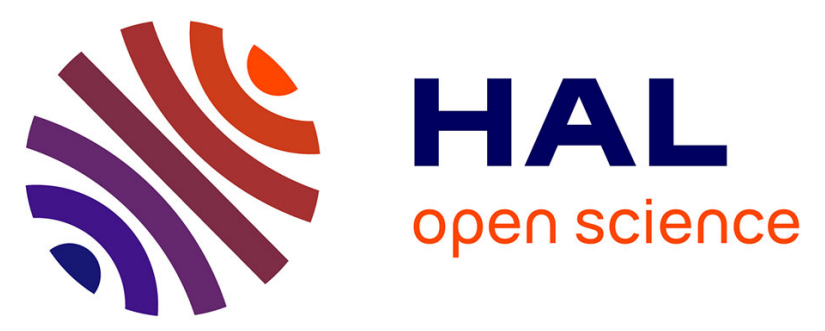

\title{
Organocatalyzed ring-opening polymerization (ROP) of functional beta-lactones: new insights into the ROP mechanism and poly(hydroxyalkanoate)s (PHAs) macromolecular structure
}

Rama M. Shakaroun, Philippe Jehan, Ali Alaaeddine, Jean-François

Carpentier, Sophie M. Guillaume

\section{To cite this version:}

Rama M. Shakaroun, Philippe Jehan, Ali Alaaeddine, Jean-François Carpentier, Sophie M. Guillaume. Organocatalyzed ring-opening polymerization (ROP) of functional beta-lactones: new insights into the ROP mechanism and poly(hydroxyalkanoate)s (PHAs) macromolecular structure. Polymer Chemistry, 2020, 11 (15), pp.2640-2652. 10.1039/d0py00125b . hal-02562365

HAL Id: hal-02562365

https://hal-univ-rennes1.archives-ouvertes.fr/hal-02562365

Submitted on 27 May 2020

HAL is a multi-disciplinary open access archive for the deposit and dissemination of scientific research documents, whether they are published or not. The documents may come from teaching and research institutions in France or abroad, or from public or private research centers.
L'archive ouverte pluridisciplinaire HAL, est destinée au dépôt et à la diffusion de documents scientifiques de niveau recherche, publiés ou non, émanant des établissements d'enseignement et de recherche français ou étrangers, des laboratoires publics ou privés. 


\title{
Organocatalyzed ring-opening polymerization (ROP) of functional $\beta$-lactones: new insights into the ROP mechanism and poly(hydroxyalkanoate)s (PHAs) macromolecular structure $\dagger$
}

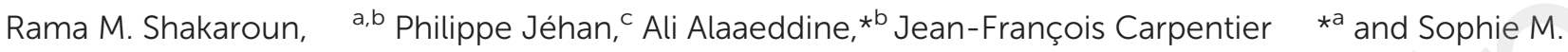 \\ Guillaume $\quad * a$
}

\begin{abstract}
${ }^{a}$ Univ. Rennes, CNRS, Institut des Sciences Chimiques de Rennes, UMR 6226, F-35042 Rennes, France. E-mail: sophie.guillaume@univ-rennes1.fr,

jean-francois.carpentier@univ-rennes1.fr

${ }^{b}$ Univ. Libanaise, Campus Universitaire Rafic Hariri Hadath, Faculté des Sciences, Laboratoire de Chimie Médicinale et des Produits Naturels, Beirut, Lebanon. E-mail: Alikassem.alaaeddine@ul.edu.lb

${ }^{c}$ Centre Régional de Mesures Physiques de l'Ouest-CRMPO, ScanMAT UMS 2001, Université de Rennes 1, France

$\dagger$ Electronic supplementary information (ESI) available: Complementing NMR and MS spectra, SEC traces of the PBPL ${ }^{\mathrm{OR}_{\mathrm{S}}}$ and kinetics of the

polymerizations of $\mathrm{BPL}^{\mathrm{OR}}$ S. See DOI: 10.1039/d0py00125b
\end{abstract}

The organocatalyzed ring-opening polymerization (ROP) of various 4-alkoxymethylene- $\beta$-propiolactones $\left(B P L{ }^{O R} ; R=C H_{2} C H=C H_{2}(A l l)\right.$, $\left.\mathrm{CH}_{2} \mathrm{Ph}(\mathrm{Bn}),\left(\mathrm{CH}_{2}\right)_{3} \mathrm{CH}_{3}\left({ }^{n} \mathrm{Bu}\right), \mathrm{SiMe}_{2}{ }^{\mathrm{t}} \mathrm{Bu}(\mathrm{TBDMS})\right)$ towards the formation of the corresponding poly(hydroxyalkanoate)s (PHAs; poly(BPL $\left.{ }^{\mathrm{OR}}\right) \mathrm{S}$ $\left(\mathrm{PBPL}{ }^{\mathrm{OR}} \mathrm{S}\right)$ ) is investigated under mild operating conditions (neat, $60^{\circ} \mathrm{C}$ ), simply using basic organocatalysts of the guanidine $(1,5,7$-triazabicyclo [4.4.0]dec-5-ene, TBD), amidine (1,8-diazabicyclo[5.4.0]-undec-7-ene, DBU) or phosphazene (2-tert-butylimino-2-diethylamino-1,3dimethylperhydro-1,3,2diazaphosphorine, BEMP) type. The polymeriza-tion proceeds basically at the same rate as the alike organocatalyzed ROP of related $\beta$-lactones (especially the ubiquitous $\beta$-butyrolactone (BL) and alkyl $\beta$-malolactonates (MLA ${ }^{R}$ s)), with BEMP being sig-nificantly more active than TBD and DBU. Insights into the polymerization mechanisms are gained through detailed 1D/2D NMR spectroscopy and MALDI-ToF mass spectrometry analyses of the resulting PBPL ${ }^{O R}$ and in particular through the identification of the nature of the end-capping groups. Each of the three organobases promotes the polymerization in its own way, as dictated by either its basic, nucleophi-lic or dual behavior.

\section{Introduction}

Poly( $\beta$-hydroxyalkanoate)s (PHAs) are natural aliphatic polyesters, produced by microorganisms from renewable biomass resources, which accumulate intracellularly in the form of granules and serve as energy storage molecules. ${ }^{1}$ Following their first report by Lemoigne in the mid-twenties, ${ }^{2}$ PHAs revealed as valuable biodegradable and biocompatible polyester materials, thereby finding applications as bulk commodity plastics or specialty polymers in various domains such as in agro-food, cosmetic, pharmaceutical or medical industries. ${ }^{3}$ However, regardless of the length and nature of the alkyl substituent of the side chain at the $\beta$-position on their backbone,

bacterial PHAs are isotactic biopolymers, thus limiting their physical, mechanical, and thermal properties, and consequently their range of uses. ${ }^{3 a, 4}$ To enable more versatility, one can synthetically introduce some functionality on the side chain, to tune, for instance, the solubility, crystallinity, hydrophobicity, degradability, thermal and mechanical properties, in order to meet specific requirements. Ring-opening polymerization (ROP) of the four-membered ring substituted $\beta$-lactones is an elected chemical approach to access such welldefined functional PHAs. ${ }^{1 b, 5}$
The ROP of various $\beta$-lactones, and more commonly of the ubiquitous prototypical $\beta$-butyrolactone (BL), has been essentially mediated by metal-based salts ${ }^{6}$ or discrete metal complexes, the latter better enabling the fine control of the molar mass, dispersity, chain-end fidelity, and stereocontrol of the microstructure. ${ }^{7}$ In particular, yttrium complexes stabilized by non-chiral tetradentate diamino or aminoalkoxy bisphenolate ligands efficiently mediate the ROP of (functional) $\beta$-lactones, ${ }^{7 i, j}$ among which $\mathrm{BL},{ }^{8}$ alkyl $\beta$-malolactonates $\left(\mathrm{MLA}^{\mathrm{R}} \mathrm{s}\right),{ }^{9}$ and more recently, 4-alkoxymethylene$\beta$-propiolactones $\left(\mathrm{BPL}^{\mathrm{OR}} \mathrm{s}\right)^{10}$ (Fig. 1) and larger 8-membered diolides, ${ }^{11}$ to give the corresponding PHAs with tuned tacticities (atactic, syndiotactic, isotactic). The $-\mathrm{CH}_{2} \mathrm{OR}$ ether groups of $\mathrm{BPL}^{\mathrm{OR}} \mathrm{S}$ and $-\mathrm{CO}_{2} \mathrm{R}$ alkoxycarbonyl groups of $\mathrm{MLA}^{\mathrm{R}} \mathrm{S}$, typi- 
(土)

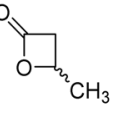

rac-BL

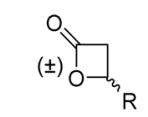

rac-MLA ${ }^{R}$

rac-MLA ${ }^{\mathrm{Me}}: \mathrm{R}=\mathrm{COOCH}_{3}$

rac-MLA All: $\mathrm{R}=\mathrm{COOCH}_{2} \mathrm{CH}=\mathrm{CH}_{2}$

rac-MLA ${ }^{\mathrm{Bn}}: \mathrm{R}=\mathrm{COOCH}_{2}\left(\mathrm{C}_{6} \mathrm{H}_{5}\right)$

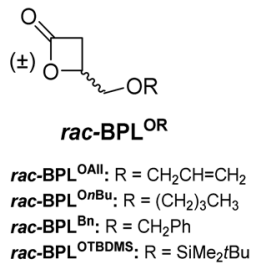

Fig. 1 Substituted $\beta$-lactones investigated in ROP towards PHAs, as reported in the literature.

cally range from benzyloxy ( $\mathrm{OBn}$; providing an hydrophilic $\mathrm{OH}$ segment upon hydrogenolysis), to alkoxy (e.g. $\mathrm{O}^{n} \mathrm{Bu}$, $\mathrm{OCH}_{2} \mathrm{CH}=\mathrm{CH}_{2}$ (OAllyl); providing an hydrophobic chain) (Fig. 1), that can be next exploited in the design of self-assemblies derived from amphiphilic copolymers, ${ }^{12}$ or valorized upon exposure to chemical modifications of the highly reactive allyl function.

Apart from metal-based catalyzed ROP, organocatalysis has been more recently revealed as another appealing approach for ROP, especially as a metal-free approach, within the context of polyesters designed for electronics and biomedical applications. Polymerization based on simple organic molecules is thus currently of topical interest for the latters' high chemical stability and long shelf live, low cost, easy availability, ease of handling and high performances. ${ }^{13}$ In fact, within the past two decades, ROP organocatalysts of the most common amine, amidine, guanidine, phosphazene or $N$-heterocyclic carbene (NHC) families, typically 4-(N,N-dimethylamino)pyridine (DMAP), 1,8-diazabicyclo[5.4.0]-undec-7-ene (DBU), 1,5,7-triazabicyclo[4.4.0]dec-5-ene (TBD), 2-tert-butylimino-2-diethylamino-1,3-dimethylperhydro-1,3,2-diazaphosphorine (BEMP), or 1,3-dimesitylimidazol-2-ylidene (IMes NHC), respectively, have proved most effective toward cyclic esters such as lactide, $\gamma$-valerolactone, and $\varepsilon$-caprolactone, as pioneered by Hedrick, Waymouth and co-workers. ${ }^{13,14}$ The organocatalyzed ROP of $\beta$-lactones is much more challenging because of their reluctance to ring open, in spite of their high ring strain. ${ }^{13,15}$ On the other hand, mechanistic pathways of organocatalyzed ROP are more diverse than those encountered in metal-based ROP. In fact, the polymerization mechanism at play in organocatalyzed ROP strongly depends on the chemical nature of the monomer, catalyst, and/or initiator. ${ }^{13}$

Among the organocatalysts used in ROP, BEMP is effective as a base $\left({ }^{\mathrm{MeCN}} \mathrm{p} K_{\mathrm{a}}=27.6\right){ }^{16}$ for assorted organic reactions such as Michaël addition and alkylation. ${ }^{17}$ Remarkably, TBD is reported as a multifunctional organocatalyst acting as a base $\left({ }^{\mathrm{MeCN}} \mathrm{p} K_{\mathrm{a}}=26.0\right){ }^{16,18 a}$ proton transfer agent ${ }^{18 b}$ or nucleophi$\operatorname{lic}^{18 c}$ catalyst for different types of reaction. DBU, discovered as a super base in the sixties ${ }^{19}$ and later identified as a nucleophile, ${ }^{20}$ recently showed a significant dual activity as a base $\left({ }^{\mathrm{MeCN}} K_{\mathrm{a}}=24.3\right)^{16}$ and nucleophile in some organic reactions. ${ }^{21}$ Investigating BEMP, TBD, and DBU in the bulk ROP of $\beta$-lactones is thus attractive and challenging.

The first reported attempt to ring-open polymerize BL using the $\mathrm{TBD} / \mathrm{ROH}$ catalytic system failed at room temperature (in

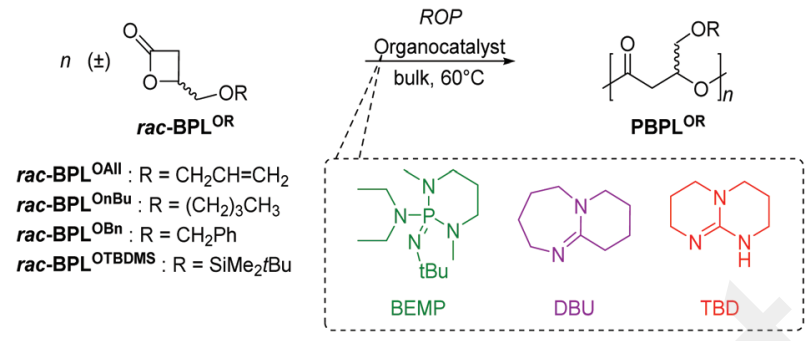

Scheme 1 Organocatalyzed ROP of rac-BPL ${ }^{\mathrm{OR}} \mathrm{s}$ towards $\mathrm{PBPL}{ }^{\mathrm{OR}} \mathrm{s}$.

$\mathrm{C}_{6} \mathrm{D}_{6}$ ), whereas increasing the temperature to $50{ }^{\circ} \mathrm{C}$ gave oligomers with crotonate byproducts in an uncontrolled reaction. ${ }^{14 a}$ Later on, TBD, BEMP and DBU successfully enabled the controlled ROP (neat, no $\mathrm{ROH}$ co-initiator, $60^{\circ} \mathrm{C}$ ) of $\mathrm{BL}$ and $\mathrm{MLA}^{\mathrm{Bn}}$ : PHB (poly(BL)) and PMLA $^{\mathrm{Bn}}$ chains apparently $\alpha, \omega$-end-capped with the base and crotonate were thus proposed, as suggested by NMR spectroscopy, SEC and MALDI-ToF MS analyses. ${ }^{22}$ A proposed mechanism with TBD involved the initial formation of a $1: 1$ organobase- $N$-acylcrotonate intermediate ${ }^{14 a}$ and propagation through monomer $O$-acyl cleavage (ESI, Scheme S1 $\dagger$ ); the ROP promoted by DBU and BEMP, although not deeply investigated, was proposed to proceed similarly. Successful copolymerization of $\mathrm{BL}$ and $\mathrm{MLA}^{\mathrm{Bn}}$ mediated by these same organocatalysts was also achieved. ${ }^{12 a, 23}$ Yet, a recent reinvestigation of the TBD promoted ROP of BL (neat, $60{ }^{\circ} \mathrm{C}$ ) by Coulembier and coworkers suggested that carboxylate anions issued from the basic activation of BL by TBD are the actual major active species, while the previously reported $N$-acyl- $\alpha, \beta$-unsaturated moiety is a minor growing species. Ultimately, the formation of $\alpha$-crotonate, $\omega$-carboxylic acid end-capped PHB derived from $\alpha$-crotonate, $\omega$ - $\mathrm{COO}^{-} \mathrm{TBDH}^{+}$PBL chains, involving an $O$-alkyl cleavage of the monomer, was claimed, as based on studies with a trisubstituted $\beta$-lactone, namely rac-benzylcarbonyl-3,3dimethyl-2-oxetanone, and ${ }^{1} \mathrm{H} / \mathrm{DOSY}$ NMR and MALDI-ToF/ESI MS data (Scheme $\mathrm{S} 1 \dagger){ }^{24}$

In light of such controversial mechanistic considerations on the ROP of substituted $\beta$-lactones, in an effort to gain further information, we herein report on the macromolecular characteristics of the PHAs issued from the organocatalyzed ROP of rac-BPL ${ }^{\mathrm{OR}} \mathrm{S}$ mediated by BEMP, TBD, or DBU (Scheme 1). Mechanistic pathways at play, specific to each organocatalyst, are proposed from detailed insights provided by $1 \mathrm{D} / 2 \mathrm{D}$ NMR spectroscopy and MALDI-ToF MS analyses of the resulting $\mathrm{PBPL}^{\mathrm{OR}} \mathrm{S}$, and more precisely through the reliable identification of the nature of their end-capping groups.

\section{Experimental section}

\section{Methods and materials}

All catalytic experiments were performed under an inert argon atmosphere using standard Schlenk line and glovebox techniques. TBD (98\%, Aldrich) was used as received. DBU (98\%, 
Aldrich) and BEMP (>98\%, Aldrich) were distilled from $\mathrm{CaH}_{2}$ prior to use. Racemic 4-benzyloxymethyl- $\beta$-propiolactone (rac$\left.\mathrm{BPL}^{\mathrm{OBn}}\right), \quad 4$-allyloxymethyl- $\beta$-propiolactone $\left(\right.$ rac-BPL $\left.^{\mathrm{OAll}}\right), 4-n$ -

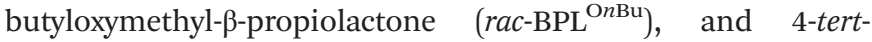
butyldimethylsilyloxymethyl- $\beta$-propiolactone (rac-BPL $^{\text {OTBDMS }}$ ) were synthesized according to the reported literature procedure, respectively. ${ }^{25}$ The lactones were dried on $\mathrm{CaH}_{2}$ and next distillated prior to use.

\section{Instrumentation and measurements}

${ }^{1} \mathrm{H} \quad(500$ and $\quad 400 \mathrm{MHz}),{ }^{13} \mathrm{C}\left\{{ }^{1} \mathrm{H}\right\} \quad(125 \mathrm{MHz}), \quad{ }^{31} \mathrm{P}\left\{{ }^{1} \mathrm{H}\right\}$ (121 MHz) and COSY NMR spectra were recorded on Bruker Avance AM 500 and Ascend 400 spectrometers at $25{ }^{\circ} \mathrm{C} .{ }^{1} \mathrm{H}$ and ${ }^{13} \mathrm{C}$ NMR spectra were referenced internally relative to

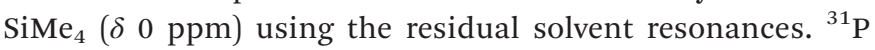
NMR spectra were referenced externally relative to $85 \%$ $\mathrm{H}_{3} \mathrm{PO}_{4}(\delta 0 \mathrm{ppm})$.

Number-average molar mass $\left(\bar{M}_{\mathrm{n}, \mathrm{SEC}}\right)$ and dispersity $\left(\bigoplus_{\mathrm{M}}=\right.$ $\left.\bar{M}_{\mathrm{w}} / \bar{M}_{\mathrm{n}}\right)$ values of the $\mathrm{PBPL}^{\mathrm{OR}} \mathrm{S}$ were determined by size exclusion chromatography (SEC) in THF at $30^{\circ} \mathrm{C}$ (flow rate $=1.0 \mathrm{~mL}$ $\mathrm{min}^{-1}$ ) on a Polymer Laboratories PL50 apparatus equipped with a refractive index detector and a set of two ResiPore PLgel $3 \mu \mathrm{m}$ MIXED-D $300 \times 7.5 \mathrm{~mm}$ columns. The polymer samples were dissolved in THF $\left(2 \mathrm{mg} \mathrm{mL}^{-1}\right)$. All elution curves were calibrated with polystyrene standards; the reported $\bar{M}_{\mathrm{n}, \mathrm{SEC}}$ values of the $\mathrm{PBPL}^{\mathrm{OR}} \mathrm{S}$ are uncorrected for the difference in hydrodynamic radius $v s$. polystyrene.

The molar mass of $\mathrm{PBPL}^{\mathrm{OR}} \mathrm{S}$ samples was determined also by ${ }^{1} \mathrm{H}$ NMR analysis $\left(\bar{M}_{\mathrm{n}, \mathrm{NMR}}\right)$ in $\mathrm{CDCl}_{3}$ from the relative intensities of the signals of the $\mathrm{PBPL}^{\mathrm{OR}}$ repeating unit methine hydrogen $\left(\mathrm{OCH}^{c}(\mathrm{R}) \mathrm{CH}_{2}, \delta_{\mathrm{Hc}} 5.76-5.19 \mathrm{ppm}\right)$ and of the crotonate chain-end hydrogen $\left(\mathrm{CH}=\mathrm{CH}{ }^{g} \mathrm{C}(\mathrm{O}), \delta_{\mathrm{Hg}} 6.99-6.08 \mathrm{ppm}\right)$.

Monomer conversions were calculated from ${ }^{1} \mathrm{H} \quad \mathrm{NMR}$ spectra of the crude reaction mixtures in $\mathrm{CDCl}_{3}$ or $\mathrm{C}_{6} \mathrm{D}_{6}$ by using the integration (Int.) ratio Int.polymer/[Int.polymer + Int.monomer] of the methine hydrogens of each polymer (as stated above) and of each residual monomer ( $\delta 4.63 \mathrm{ppm}$ for $\mathrm{BPL}^{\mathrm{OBn}}, \delta 4.65 \mathrm{ppm}$ for $\mathrm{BPL}^{\mathrm{OAll}}, \delta 4.66 \mathrm{ppm}$ for $\mathrm{BPL}^{\mathrm{O} n \mathrm{Bu}}$ and $\delta$ $4.54 \mathrm{ppm}$ for $\mathrm{BPL}^{\text {OTBDMS }}$, in $\mathrm{CDCl}_{3}$ ).

Mass spectra were recorded at CRMPO-ScanMAT (Rennes, France). ESI mass spectra were recorded on an orbitrap type Thermo Fisher Scientific Q-Exactive instrument with an ESI source in positive or negative mode by direct introduction at 5-10 $\mu \mathrm{g} \mathrm{mL} \mathrm{m}^{-1}$. Samples were prepared in $\mathrm{CH}_{2} \mathrm{Cl}_{2}$ at $10 \mu \mathrm{g}$ $\mathrm{mL}^{-1}$. High resolution MALDI-ToF mass spectra were recorded using an ULTRAFLEX III TOF/TOF spectrometer (Bruker Daltonik Gmbh, Bremen, Germany) in positive and/or negative ionization mode. Spectra were recorded using reflectron mode and an accelerating voltage of $25 \mathrm{kV}$. A mixture of a freshly prepared solution of the polymer in THF or $\mathrm{CH}_{2} \mathrm{Cl}_{2}$ (HPLC grade, $10 \mathrm{mg} \mathrm{mL} \mathrm{mL}^{-1}$ and DCTB (trans-2-(3-(4-tert-butylphenyl)2methyl-2-propenylidene) malononitrile, and a $\mathrm{MeOH}$ solution of the cationizing agent ( $\mathrm{NaI}, 10 \mathrm{mg} \mathrm{mL}^{-1}$ ) were prepared. The solutions were combined in a $1: 1: 1 \mathrm{v} / \mathrm{v} / \mathrm{v}$ ratio of matrix-tosample-to-cationizing agent - if added. The resulting solution $(0.25-0.5 \mathrm{~mL})$ was deposited onto the sample target
(Prespotted AnchorChip PAC II 384/96 HCCA) and air or vacuum dried.

\section{General procedure for $\mathrm{BPL}^{\mathrm{OR}} \mathrm{S}$ homopolymerization}

In a typical experiment (Table 1, entry 12), in a glovebox, BEMP $(10 \mu \mathrm{L}, 34.6 \mu \mathrm{mol})$ was added using a microsyringe onto $\mathrm{BPL}^{\mathrm{OBn}}(0.28 \mathrm{~g}, 1.475 \mathrm{mmol}, 42$ equiv.) placed in a Schlenk flask. The neat reaction mixture was then stirred in an oil bath at $60{ }^{\circ} \mathrm{C}$ over the appropriate reaction time (reaction times were not systematically optimized). The polymerization was quenched by addition of an excess of undried $\mathrm{CH}_{2} \mathrm{Cl}_{2}(1 \mathrm{~mL})$. The resulting mixture was concentrated to dryness under vacuum and the conversion was determined by ${ }^{1} \mathrm{H}$ NMR analysis of the residue dissolved in $\mathrm{CDCl}_{3}$ or $\mathrm{C}_{6} \mathrm{D}_{6}$. The crude residue was then dissolved in $\mathrm{CH}_{2} \mathrm{Cl}_{2}(1 \mathrm{~mL})$ and precipitated in cold pentane $\left(10 \mathrm{~mL}, 0{ }^{\circ} \mathrm{C}\right.$ ) (repeated twice, thus enabling the removal of potential unreacted/free base), filtered and dried overnight at $60{ }^{\circ} \mathrm{C}$ using a vacuum oven. All recovered polymers were then analyzed by NMR, MALDI-ToF and ESI MS, and SEC (refer to $\mathrm{ESI}_{\dagger} \dagger$ ). $\mathrm{PBL}^{\mathrm{OR}}$ samples were stored under inert atmosphere at $0^{\circ} \mathrm{C}$.

\section{Results and discussion}

The organocatalyzed ROP of $r a c-\mathrm{BPL}^{\mathrm{OR}} \mathrm{S}$ has been investigated using BEMP, TBD or DBU, under neat conditions (solventfree), at $23-60{ }^{\circ} \mathrm{C}$, in the absence of an alcohol as co-initiator. These operating conditions were the same as those previously implemented in the successful alike ROP of BL and $\mathrm{MLA}^{\mathrm{Bn}} \cdot{ }^{22,26}$ Representative results of these ROP experiments are gathered in Tables 1-3. Insights into the chemical structure of the resulting $\mathrm{PBPL}^{\mathrm{OR}} \mathrm{S}$ were gained from detailed NMR spectroscopy and MS investigations. Close examination of the nature of the chain-end groups then supported different operating modes for each organocatalyst.

\section{General characteristics of the ROP of rac-BPL ${ }^{\mathrm{OR}} \mathrm{S}$ mediated by BEMP, TBD or BDU}

The neat ROP of $r a c-\mathrm{BPL}^{\mathrm{OR}} \mathrm{S}$ has been first investigated using BEMP as catalyst. While effective at room temperature, the polymerization was found, as expected, to proceed faster at higher temperatures (40 or $60{ }^{\circ} \mathrm{C}$; Table 1). Subsequent ROP experiments of $\mathrm{BPL}^{\mathrm{OR}} \mathrm{S}$ were thus all performed at $60{ }^{\circ} \mathrm{C}$ (Tables 1-3).

The nature of the ether moiety of the $\mathrm{CH}_{2} \mathrm{OR}$ group appeared to similarly influence the rate of the polymerization from one organocatalyst to another, as revealed by kinetic monitoring by ${ }^{1} \mathrm{H}$ NMR spectroscopy of the ROP of $r a c-\mathrm{BPL}^{\mathrm{OR}} \mathrm{S}$ (Fig. 2). Using BEMP, TBD or DBU, while $\mathrm{BPL}^{\mathrm{OBn}}$ exhibited a slightly faster rate of polymerization than $\mathrm{BPL}^{\mathrm{O} n \mathrm{Bu}}$, both monomers polymerized less rapidly than $\mathrm{BPL}^{\mathrm{OAll}}$, but much faster than BPL ${ }^{\text {OTBDMS }}$ (Fig. 2, Tables 1-3). Regardless of the ether moiety, the $\mathrm{BPL}^{\mathrm{OR}} \mathrm{S}$ polymerized significantly more slowly (typical turnover frequency (TOF) $<15 \mathrm{~h}^{-1}$ ) than $\beta$-butyrolactone and alkyl $\beta$-malolactonates $\operatorname{MLA}^{\mathrm{R}} \mathrm{S}$ (typical 

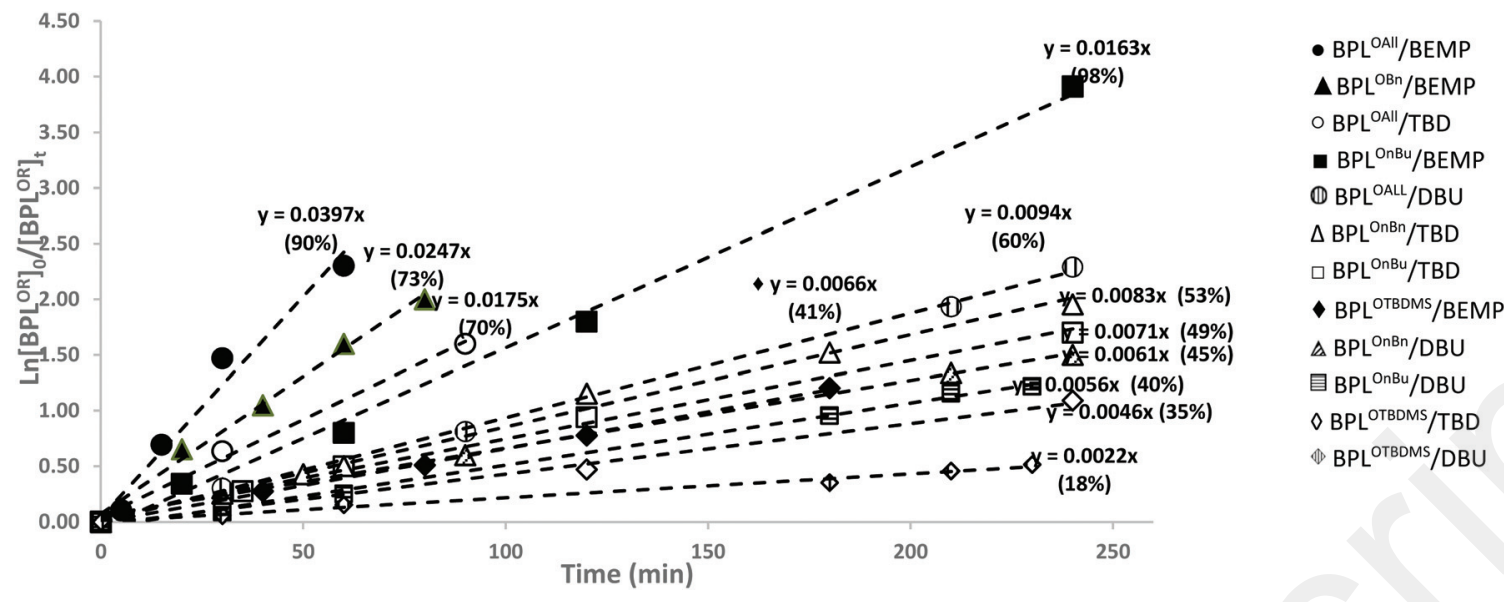

Fig. 2 Logarithmic plot of the kinetics of the ROP of rac-BPL ${ }^{O R}$ (40 equiv.) mediated by BEMP (1 equiv.) (Table 1, entries $3,6,12$ and 15 ), TBD (Table 2, entries 1, 4, 7 and 8) and DBU (Table 3, entries 1-4), at $60{ }^{\circ} \mathrm{C}$ in bulk; the data in parentheses are the final monomer conversions (before reaching a high viscosity and diffusion limits).

TOF $=100 \mathrm{~h}^{-1}$, and $150 \mathrm{~h}^{-1}$, respectively) under the same conditions. $^{22}$ BEMP proved significantly more active than TBD and $\mathrm{DBU}$, a general trend also reported for the alike ROP of $\mathrm{BL}$ and $\mathrm{MLA}^{\mathrm{Bn}}$. $^{22}$ Also, the organocatalysts herein investigated revealed less efficient than the yttrium-based catalyst which typically afforded the corresponding $\mathrm{PBPL}^{\mathrm{OR}} \mathrm{S}$ with quantitative yields within $2 \mathrm{~h}$ at $23{ }^{\circ} \mathrm{C}\left(\mathrm{TOF}=c a .25 \mathrm{~h}^{-1}\right) \cdot{ }^{10 a}$ Note that, in contrast to syndio- and isotactic polymers produced by bisphenolate yttrium catalysts, ${ }^{10}$ all $\mathrm{PBPL}^{\mathrm{OBn}} \mathrm{s}$ recovered from the three organocatalysts revealed atactic, as evidenced by the ${ }^{13} \mathrm{C}$ $\left\{{ }^{1} \mathrm{H}\right\}$ NMR spectra (ESI, Fig. S1†).

The molar masses were evaluated by ${ }^{1} \mathrm{H}$ NMR analysis $\left(\bar{M}_{\mathrm{n}, \mathrm{NMR}}\right)$ from the relative intensities of the signals of the $\mathrm{PBPL}^{\mathrm{OR}}$ main-chain methine hydrogen and of the crotonate chain-end (vide infra) hydrogens (refer to the Experimental section). These values generally increased proportionally to the monomer loading and remained in fair agreement with the molar mass values calculated from the monomer conversion ( $\bar{M}_{\mathrm{n}, \text { theo; }}$ not taking into account end-capping groups). The number-average molar mass values as determined by SEC $\left(\bar{M}_{\mathrm{n}, \mathrm{SEC}}\right)$ were also generally in fair agreement with the $\bar{M}_{\mathrm{n}, \mathrm{NMR}}$ data. The dispersities $\left(\bigoplus_{\mathrm{M}}\right)$, in the range 1.09-1.53 (ESI, Fig. S2 $\uparrow$ ), most likely evidenced the occurring, yet with a limited extent, of undesirable intra- and intermolecular transesterification reactions (backbiting and reshuffling, respectively) or other transfer reactions (vide infra), or possibly a rate of initiation competitive with that of propagation. The control in terms of molar mass and limited side reactions, and the catalytic activity

Table 1 Characteristics of the $\mathrm{PBPL}^{\mathrm{OR}} \mathrm{S}$ synthesized by ROP of rac- $\mathrm{BPL}{ }^{\mathrm{OR}} \mathrm{S}$ mediated by $\mathrm{BEMP}$

\begin{tabular}{|c|c|c|c|c|c|c|c|c|c|}
\hline Entry & $\mathrm{BPL}^{\mathrm{OR}}$ & $\begin{array}{l}{\left[\mathrm{BPL}^{\mathrm{OR}}\right]_{0} /} \\
{[\mathrm{BEMP}]_{0}}\end{array}$ & $\begin{array}{l}\text { Temp. } \\
\left({ }^{\circ} \mathrm{C}\right)\end{array}$ & $\begin{array}{l}\text { Reaction time }{ }^{b} \\
\text { (h) }\end{array}$ & $\begin{array}{l}\text { Conv. }^{c} \\
(\%)\end{array}$ & $\begin{array}{l}\bar{M}_{\mathrm{n}, \text { theo }}{ }^{d} \\
\left(\mathrm{~g} \mathrm{~mol}^{-1}\right)\end{array}$ & $\begin{array}{l}\bar{M}_{\mathrm{n}, \mathrm{NMR}}{ }^{e} \\
\left(\mathrm{~g} \mathrm{~mol}^{-1}\right)\end{array}$ & $\begin{array}{l}\bar{M}_{\mathrm{n}, \mathrm{SEC}}{ }^{f} \\
\left(\mathrm{~g} \mathrm{~mol}^{-1}\right)\end{array}$ & $D_{\mathrm{M}}^{f}$ \\
\hline 1 & $\mathrm{BPL}^{\text {OAll }}$ & 40 & 25 & 21 & 91 & 5150 & 4100 & 4600 & 1.09 \\
\hline 2 & $\mathrm{BPL}^{\text {OAll }}$ & 40 & 40 & 7 & 50 & 2850 & 1800 & 1300 & 1.17 \\
\hline 3 & $\mathrm{BPL}^{\text {OAll }}$ & 40 & 60 & 3 & 97 & 5500 & 4800 & 3900 & 1.26 \\
\hline 4 & $\mathrm{BPL}^{\mathrm{O} n \mathrm{Bu}}$ & 40 & 25 & 19 & 72 & 4550 & 4850 & 6200 & 1.18 \\
\hline 5 & $\mathrm{BPL}^{\mathrm{O} n \mathrm{Bu}}$ & 44 & 40 & 8 & 78 & 5400 & 5650 & 7700 & 1.16 \\
\hline 6 & $\mathrm{BPL}^{\mathrm{O} n \mathrm{Bu}}$ & 40 & 60 & 4 & 98 & 6200 & 3800 & 4900 & 1.32 \\
\hline 7 & $\mathrm{BPL}^{\mathrm{OBn}}$ & 43 & 25 & 12 & 60 & 4950 & 3300 & 2800 & 1.53 \\
\hline 8 & $\mathrm{BPL}^{\mathrm{OBn}}$ & 15 & 40 & 3 & 94 & 2700 & 3100 & 2500 & 1.32 \\
\hline 9 & $\mathrm{BPL}^{\mathrm{OBn}}$ & 40 & 40 & 9 & 84 & 6450 & 5500 & 5000 & 1.15 \\
\hline 10 & $\mathrm{BPL}^{\mathrm{OBn}}$ & 60 & 40 & 10 & 32 & 3700 & 1700 & 1500 & 1.38 \\
\hline 11 & $\mathrm{BPL}^{\mathrm{OBn}}$ & 15 & 60 & 4 & 100 & 2900 & 2500 & 2400 & 1.21 \\
\hline 12 & $\mathrm{BPL}^{\mathrm{OBn}}$ & 40 & 60 & 3 & 82 & 6300 & 4200 & 3100 & 1.27 \\
\hline 13 & $\mathrm{BPL}^{\mathrm{OBn}}$ & 60 & 60 & 2 & 50 & 5750 & 3000 & 2800 & 1.53 \\
\hline 14 & $\mathrm{BPL}^{\text {OTBDMS }}$ & 40 & 40 & 6 & 34 & 2950 & 2000 & 1900 & 1.20 \\
\hline 15 & $\mathrm{BPL}^{\text {OTBDMS }}$ & 35 & 60 & 8 & 88 & 6650 & 3600 & 3300 & 1.18 \\
\hline
\end{tabular}

${ }^{a}$ Results are representative of at least duplicated experiments performed neat. ${ }^{b}$ The reaction time was not necessarily optimized. ${ }^{c}$ BPL ${ }^{\text {OR }}$ conversion as determined by ${ }^{1} \mathrm{H}$ NMR analysis of the crude reaction mixture (refer to the Experimental section). ${ }^{d}$ Theoretical molar mass calculated from the relation: $\left[\mathrm{BPL}^{\mathrm{OR}}\right]_{\mathrm{o}} /[\mathrm{BEMP}]_{\mathrm{o}} \times \mathrm{Conv}_{\cdot \mathrm{BPLOR}} \times M_{\mathrm{BPLOR}}$, i.e. without considering end-capping groups, with $M_{\mathrm{BPLOAll}}=142 \mathrm{~g}$ mol ${ }^{-1}, M_{\mathrm{BPLO} n \mathrm{Bu}}=$ $158 \mathrm{~g} \mathrm{~mol}^{-1}, M_{\mathrm{BPLBn}}=192 \mathrm{~g} \mathrm{~mol}^{-1}$, and $M_{\mathrm{BPLOTBDMS}}=216 \mathrm{~g} \mathrm{~mol}^{-1}$. ${ }^{e}$ Experimental molar mass value determined by ${ }^{1} \mathrm{H}$ NMR analysis of the isolated polymer, from the resonances of the crotonate end-group (refer to the Experimental section). ${ }^{f}$ Experimental molar mass and dispersity values as determined by SEC in THF using a RI detector at $30^{\circ} \mathrm{C} v s$. polystyrene standards. 
Table 2 Characteristics of the $\mathrm{PBPL}^{\mathrm{OR}} \mathrm{S}$ synthesized by ROP of rac-BPL ${ }^{\mathrm{OR}} \mathrm{S}$ mediated by $\mathrm{TBD}^{\mathrm{a}}$

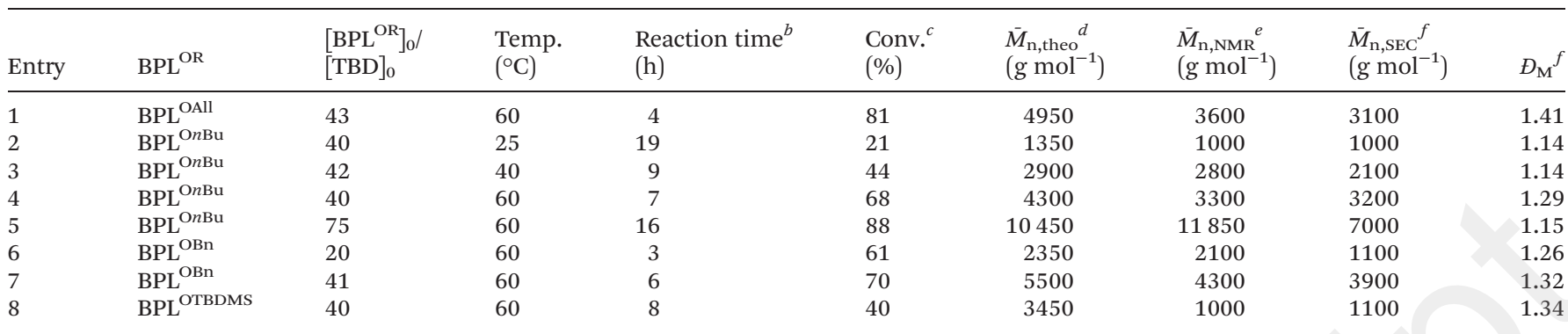

${ }^{a}$ Results are representative of at least duplicated experiments performed neat. ${ }^{b}$ The reaction time was not necessarily optimized. ${ }^{c}$ BPL ${ }^{\text {OR }}$ conver- $^{\circ}$ sion as determined by ${ }^{1} \mathrm{H}$ NMR analysis of the crude reaction mixture (refer to the Experimental section). ${ }^{d}$ Theoretical molar mass calculated from the relation: $\left[\mathrm{BPL}^{\mathrm{OR}}\right]_{0} /[\mathrm{TBD}]_{0} \times \mathrm{COnv}_{\cdot \mathrm{BPLOR}} \times M_{\mathrm{BPLOR}}$, i.e. without considering end-capping groups, with $M_{\mathrm{BPLOAll}}=142 \mathrm{~g}$ mol ${ }^{-1}, M_{\mathrm{BPLO} n \mathrm{Bu}}=$ $158 \mathrm{~g} \mathrm{~mol}^{-1}, M_{\mathrm{BPLOBn}}=192 \mathrm{~g} \mathrm{~mol}^{-1}$, and $M_{\mathrm{BPLOTBDMS}}=216 \mathrm{~g} \mathrm{~mol}^{-1} \cdot{ }^{e}$ Experimental molar mass value as determined by ${ }^{1} \mathrm{H}$ NMR analysis of the isolated polymer, from the resonances of the crotonate end-group (refer to the Experimental section). ${ }^{f}$ Experimental molar mass and dispersity values as determined by SEC in THF using a RI detector at $30^{\circ} \mathrm{C} v s$. polystyrene standards.

Table 3 Characteristics of the $\mathrm{PBPL}^{\mathrm{OR}} \mathrm{s}$ synthesized by ROP of rac-BPL ${ }^{\mathrm{OR}} \mathrm{s}$ mediated by $\mathrm{DBU}^{\mathrm{a}}$

\begin{tabular}{|c|c|c|c|c|c|c|c|c|}
\hline Entry & $\mathrm{BPL}^{\mathrm{OR}}$ & $\begin{array}{l}{\left[\mathrm{BPL}^{\mathrm{OR}}\right]_{0} /} \\
{[\mathrm{DBU}]_{0}}\end{array}$ & $\begin{array}{l}\text { Reaction time }{ }^{b} \\
\text { (h) }\end{array}$ & $\begin{array}{l}\text { Conv. }{ }^{c} \\
(\%)\end{array}$ & $\begin{array}{l}\bar{M}_{\mathrm{n}, \text { theo }}{ }^{d} \\
\left(\mathrm{~g} \mathrm{~mol}^{-1}\right)\end{array}$ & $\begin{array}{l}\left.\bar{M}_{\mathrm{n}, \mathrm{NMR}^{e}}{ }^{-1}\right) \\
\left(\mathrm{g} \mathrm{mol}^{-1}\right)\end{array}$ & $\begin{array}{l}\bar{M}_{\mathrm{n}, \mathrm{SEC}}{ }^{f} \\
\left(\mathrm{~g} \mathrm{~mol}^{-1}\right)\end{array}$ & $D_{\mathrm{M}}^{f}$ \\
\hline 1 & $\mathrm{BPL}^{\text {OAll }}$ & 40 & 8 & 58 & 3300 & 1700 & 1300 & 1.18 \\
\hline 4 & BPL $^{\text {OTBDMS }}$ & 40 & 8 & 25 & 2200 & 2600 & 1800 & 1.12 \\
\hline
\end{tabular}

${ }^{a}$ Results are representative of at least duplicated experiments performed neat at $60{ }^{\circ} \mathrm{C} .{ }^{b}$ The reaction time was not necessarily optimized. ${ }^{c} \mathrm{BPL}{ }^{\mathrm{OR}}$ conversion as determined by ${ }^{1} \mathrm{H}$ NMR analysis of the crude reaction mixture (refer to the Experimental section). ${ }^{d}$ Theoretical molar mass calculated from the relation: $\left[\mathrm{BPL}^{\mathrm{OR}}\right]_{0} /[\mathrm{DBU}]_{0} \times \mathrm{Conv}_{\cdot \mathrm{BPLOR}} \times M_{\mathrm{BPLO}}$, i.e. without considering end-capping groups, with $M_{\mathrm{BPLOAll}}=142 \mathrm{~g}$ mol ${ }^{-1}$, $M_{\mathrm{BPLO} \text { Bu }}=158 \mathrm{~g} \mathrm{~mol}^{-1}, M_{\mathrm{BPLOBn}}=192 \mathrm{~g} \mathrm{~mol}^{-1}$, and $M_{\mathrm{BPLOTBDMS}}=216 \mathrm{~g} \mathrm{~mol}^{-1} \cdot{ }^{e}$ Experimental molar mass value as determined by ${ }^{1} \mathrm{H} \mathrm{NMR} \mathrm{ana-}$ lysis of the isolated polymer, from the resonances of the crotonate end-group (refer to the Experimental section). ${ }^{f}$ Experimental molar mass and dispersity values as determined by SEC in THF using a RI detector at $30^{\circ} \mathrm{C} v \boldsymbol{s}$. polystyrene standards.

and productivity, were not optimized, since the focus of the present work was placed on the mechanism at play.

NMR, MALDI-ToF and ESI MS of the PBPL ${ }^{\mathrm{OR}} \mathrm{S}$ and mechanistic insights into the ROP of rac-BPL ${ }^{\mathrm{OR}}$ mediated by BEMP, TBD or DBU

All the purified (reprecipitated twice - refer to the Experimental section) $\mathrm{PBPL}^{\mathrm{OR}} \mathrm{S}$ samples isolated from the ROP of $r a c-\mathrm{BPL}^{\mathrm{OR}} \mathrm{S}$ mediated by BEMP, TBD or DBU were characterized by ${ }^{1} \mathrm{H}$, J-MOD and 2D (COSY) NMR spectroscopy and MALDI-ToF and ESI MS (refer to ESI $\dagger$ ). These analyses enabled to probe the nature of the end-capping groups of the PHAs and therefrom to suggest the possible corresponding ROP mechanism specific to each organocatalyst.

\section{$\mathrm{PBPL}^{\mathrm{OR}} \mathrm{S}$ recovered from the ROP of $\mathrm{rac}-\mathrm{BPL}^{\mathrm{OR}} \mathrm{S}$ mediated by BEMP}

The typical ${ }^{1} \mathrm{H}$ and J-MOD NMR spectra of $\mathrm{PBPL}^{\mathrm{ORn}} \mathrm{S}$ recovered from the ROP of $\mathrm{rac}^{\mathrm{BPL}}{ }^{\mathrm{OR}} \mathrm{S}$ mediated by BEMP (Table 1, Fig. S3-S5 $\dagger$ ) are depicted in Fig. 3 with $\mathrm{PBPL}^{\mathrm{OBn}}$. Regardless of the monomer/polymer ether substituent (OBn, OAll, $\mathrm{O}^{n} \mathrm{Bu}$, OTBDMS), besides the main chain repeating unit typical methine and methylene backbone hydrogens' signals $\left(\delta_{1_{\mathrm{H}}} \mathrm{ppm}\right.$ $5.39\left(\mathrm{OCH}^{c} \mathrm{CH}_{2}\right)$ and $\left.2.67\left(\mathrm{CH}_{2}{ }^{a, b} \mathrm{C}(\mathrm{O})\right)\right)$, resonances for both crotonate $\left(\delta_{1_{\mathrm{H}}}\right.$ ppm $6.99\left(\mathrm{CH}^{h}=\mathrm{CHCH}_{2} \mathrm{O}\right), 6.14\left(\mathrm{CH}=\mathrm{C} H^{g} \mathrm{C}(\mathrm{O})\right.$
O)) and BEMP (especially methyl signals: $\delta_{1_{\mathrm{H}}}$ ppm 1.36 (NC $\left.\left(\mathrm{CH}_{3}^{j}\right)_{3}\right)$ and $\left.1.15\left(\mathrm{NCH}_{2} \mathrm{CH}_{3}^{k}\right)\right)$ moieties were clearly observed. The corresponding carbon signals of these two moieties were assigned from the J-MOD spectrum (Fig. 3). All signals' assignments were supported by 2D COSY NMR analyses; the correlation between the vinylic hydrogens and the end-group methylene hydrogens supports a crotonate chain-end (ESI, Fig. S6-S10 $\dagger$ ). ${ }^{1} \mathrm{H}$ NMR monitoring of the $\alpha, \beta$-unsaturation-toBEMP molar ratio revealed an increase of the crotonate group content during the course of the reaction and/or at a higher temperature $\left(60^{\circ} \mathrm{C}\right)$ and/or at a larger initial monomer loading (40 vs. 60 equiv.) (Table 1, entries 9, 10, 12 and 13; ESI, Fig. S11†), in agreement with the suggested mechanism (Scheme 2, vide infra). Closer examination of the ${ }^{1} \mathrm{H}$ NMR signals of the BEMP moiety, and as further corroborated by ${ }^{31} \mathrm{P}$ NMR analysis, showed that the resonances correspond to the protonated base $[\mathrm{BEMPH}]^{+}$; this was demonstrated by the significant shift of the $\mathrm{NC}\left(\mathrm{CHj}^{3}\right)_{3}{ }^{1} \mathrm{H}(\Delta \delta-0.25 \mathrm{ppm})$ and ${ }^{31} \mathrm{P}(\Delta \delta$ $27.18 \mathrm{ppm})$ resonances, relative to the free BEMP signals, respectively, and by the comparison with a genuine sample of $[\mathrm{BEMPH}]^{+}[\mathrm{OAc}]^{-}$(ESI, Fig. S12 $\dagger$ ). Hence, BEMP is present in its protonated form $[\mathrm{BEMPH}]^{+}$during the polymerization process, excluding the possibility of it behaving as a nucleophile that would ring open the monomer via an $O$-acyl cleavage. 

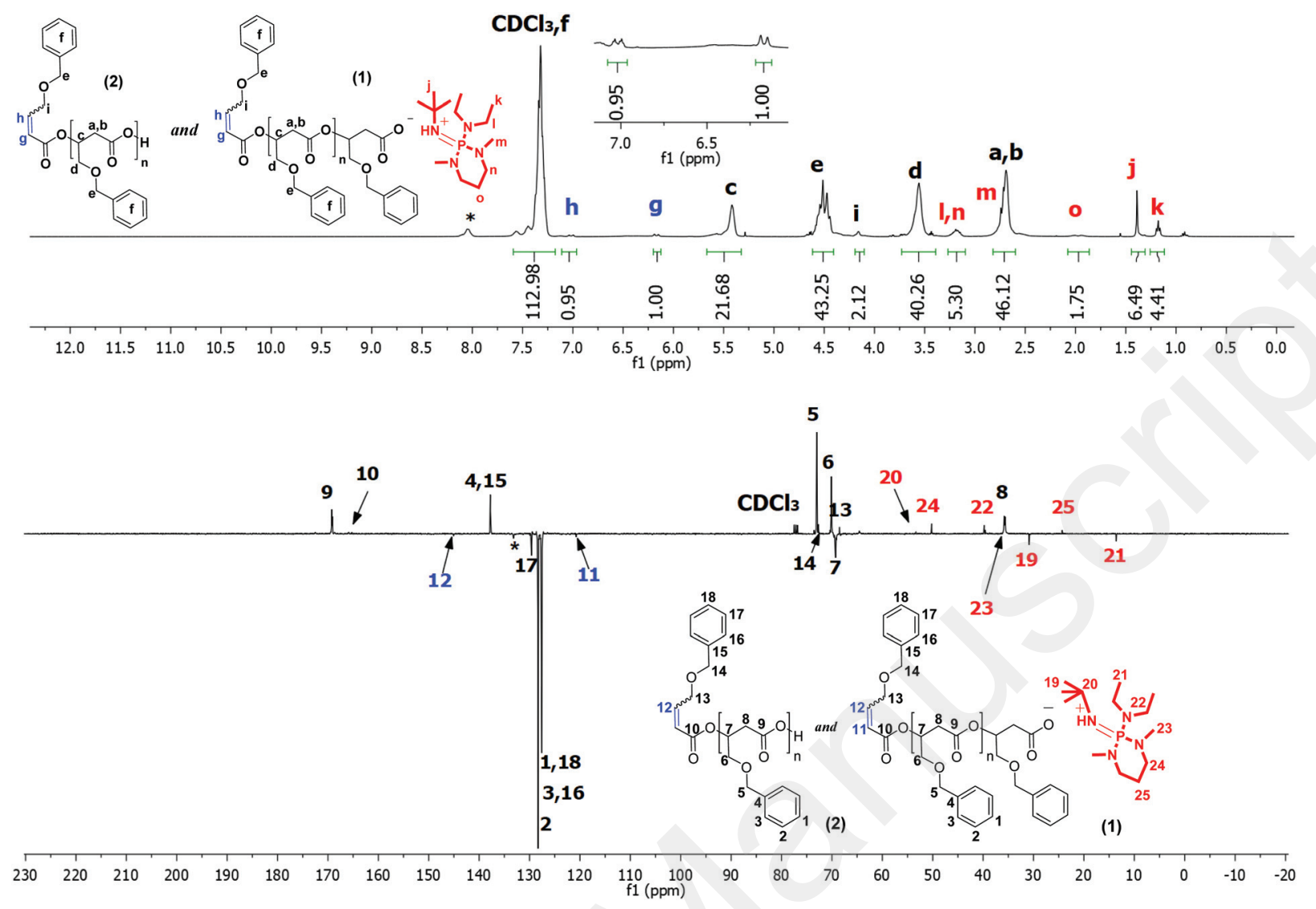

Fig. $3{ }^{1} \mathrm{H}\left(500 \mathrm{MHz}, \mathrm{CDCl}_{3}, 25^{\circ} \mathrm{C}\right)$ (top) and J-MOD $\left(125 \mathrm{MHz}_{2} \mathrm{CDCl}_{3}, 25{ }^{\circ} \mathrm{C}\right.$ ) (bottom) NMR spectra of $\mathrm{PBPL}{ }^{\mathrm{OBn}}$ with $\left[\mathrm{BnOCH} \mathrm{CH}^{\circ}=\mathrm{CHCOO}\right.$ $\left.\left(\mathrm{PBL}{ }^{\mathrm{OBn}}\right)\right]^{-}[\mathrm{BEMPH}]^{+}(\mathrm{Scheme} 2,1)$ and $\mathrm{BnOCH}_{2} \mathrm{CH}=\mathrm{CHCOO}\left(\mathrm{PBL}{ }^{\mathrm{OBn}}\right) \mathrm{H}(\mathrm{Scheme} 2,2)$ (note that the possible $\left[\mathrm{BnOCH} \mathrm{CH}_{2}=\mathrm{CHCOO}^{-}[\mathrm{BEMPH}]^{+}\right.$ species (Scheme 2,3 ) is not depicted) recovered from the ROP of rac-BPL ${ }^{\mathrm{OBn}}$ mediated by BEMP (Table 1 , entry 12) (*: unidentified minor impurity not observed in other spectra of PBPL ${ }^{\mathrm{OR}}$ obtained from BEMP (ESI, Fig. S3-S7 $\dagger$ )).

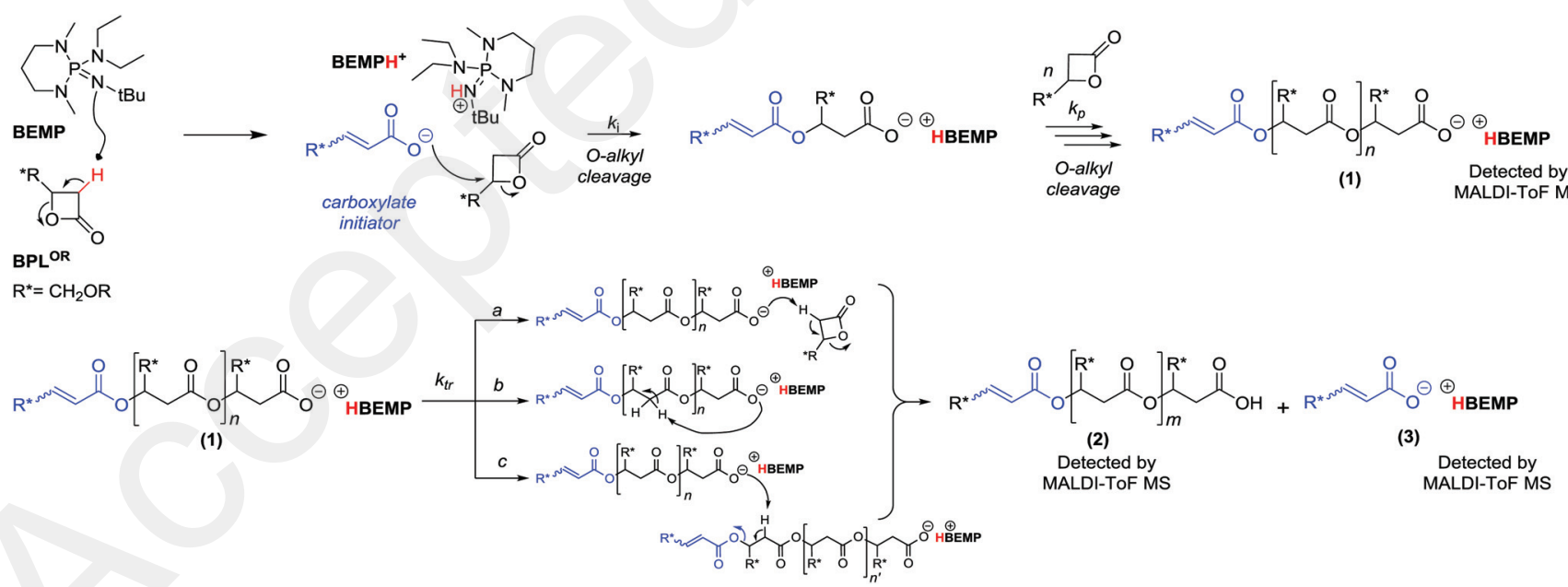

Scheme 2 Proposed mechanism for the ROP of rac-BPL ${ }^{\mathrm{OR}} \mathrm{S}$ mediated by BEMP proceeding via a proton transfer reaction to generate in situ the carboxylate initiating moiety $\left(k_{i}, k_{p}, k_{t r}\right.$, refer to the rate constant of initiation, propagation, and transfer reactions, respectively), showing the various macromolecular species (1-3).

The MALDI-ToF (Fig. 4) and ESI (ESI, Fig. S13†) mass spectra of $\mathrm{PBPL}^{\mathrm{OBn}}$ samples prepared by the BEMP-mediated ROP are both consistent with the above-mentioned $\alpha$-crotonate, $\omega$-carboxylic acid terminated polymer. Indeed, the spectra showed a major population of $\mathrm{PBPL}^{\mathrm{OBn}}$ with a repeating unit of $192 \mathrm{~g} \mathrm{~mol}^{-1}$ end-capped with a benzyloxycrotonate 


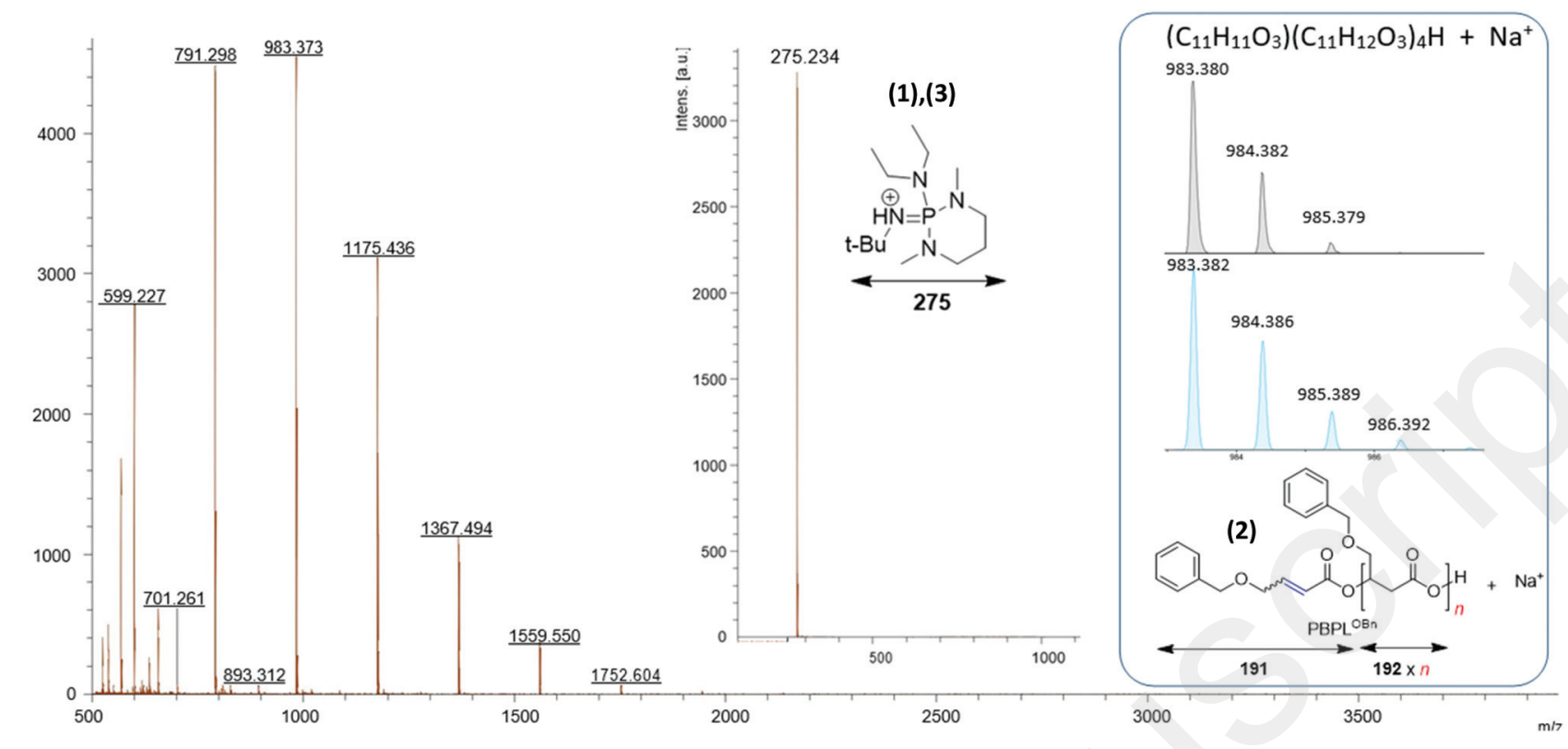

Fig. 4 MALDI-ToF mass spectrum (positive mode, DCTB matrix, $\mathrm{Na}^{+}$cationizing salt) of a sample freshly synthesized from the ROP of rac-BPL ${ }^{\mathrm{Bn}}$ mediated by BEMP (Table 1, entry 11) showing populations corresponding to $\mathrm{PBPL}^{\mathrm{OBn}}$ macromolecules end-capped with both an $\alpha$-crotonate and an $\omega$-carboxylic acid end-groups (Scheme 2, 2; the right zoomed regions correspond to the simulated (blue, bottom) and experimental (black, top) spectra), and to $[\mathrm{BEMPH}]^{+}$(Scheme 2, 1,3; the top middle zoomed region shows the $[\mathrm{BEMPH}]^{+}$fragment recorded).

and a carboxylic acid groups (the latter which was not observed in the ${ }^{1} \mathrm{H},{ }^{13} \mathrm{C}$ or HMBC NMR spectra; ESI, Fig. S1, S10†), as unequivocally supported by the close match of the simulated isotopic distribution with e.g. $m / z_{\exp }=983.380 \mathrm{~g} \mathrm{~mol}^{-1} v s$. $m / z_{\text {simul }}=983.382 \mathrm{~g} \mathrm{~mol}^{-1}$ for $n=4$ (see right zoomed region). $[\mathrm{BEMPH}]^{+}$was also clearly observed at $\mathrm{m} / \mathrm{z}_{\exp }=275.234 \mathrm{~g}$ $\mathrm{mol}^{-1}$ (middle zoomed region) vs. $m / z_{\text {simul }}=275.236 \mathrm{~g} \mathrm{~mol}^{-1}$. However, its counter anion, the carboxylate (macro)molecule(s) (Scheme 2-1,3) could not be observed under the positive MALDI-ToF MS conditions while analysis under the negative mode did not revealed sensitive enough. No cyclic polymer therein was observed. ${ }^{27}$

Considering these spectroscopic and spectrometric evidences of the formation of a mixture of $\alpha$-benzyloxy crotonate, $\omega-\mathrm{COOH} \mathrm{PBPL}^{\mathrm{OBn}}$ and $[\mathrm{BEMPH}]^{+}$, we may propose the ROP mechanism depicted in Scheme 2. Thus, BEMP would act as a basic pre-initiator that abstracts one of the methylene hydrogen in $\alpha$-position of the $\mathrm{BPL}^{\mathrm{OR}}$ monomer, thereby generating an $\alpha, \beta$-unsaturated carboxylate species as the real initiator, which in turn would propagate the polymerization via $O$-alkyl cleavage of further incoming monomer units. Carboxylate initiators have previously been reported to promote the ROP of BL and MLA ${ }^{\mathrm{Bn}}$ through such $O$-alkyl opening, a behavior specific to $\beta$-lactones. ${ }^{5,28}$ Ultimately, $\left(\mathrm{ROCH}_{2} \mathrm{CH}=\mathrm{CHC}(\mathrm{O}) \mathrm{O}\right)-\mathrm{PBPL}^{\mathrm{OBn}}-\mathrm{H}$ chains would form upon termination/transfer reactions. Transfer reactions may (a) involve the monomer $\left(k_{\mathrm{tr}, \mathrm{a}}\right)$, (b) take place intramolecularly $\left(k_{\mathrm{tr}, \mathrm{b}}\right)$, and/or (c) intermolecularly $\left(k_{\mathrm{tr}, \mathrm{c}}\right)$, eventually generating a shorter active macromolecular chain ready to propagate (similar to 1), a dormant chain with a carboxylic acid endgroup (2), and/or the carboxylate initiator $\left[\mathrm{BnOCH}_{2} \mathrm{CH}=\mathrm{CHC}\right.$
$(\mathrm{O}) \mathrm{O}]^{-}[\mathrm{BEMPH}]^{+}$(3). Such side-reactions could, besides a possible slow initiation, account for the slight discrepancies between experimental molar mass values $\left(\bar{M}_{\mathrm{n}, \mathrm{SEC}}, \bar{M}_{\mathrm{n}, \mathrm{NMR}}\right)$ and $\bar{M}_{\mathrm{n}, \text { theo }}$ as well as for the slightly broad dispersities. ${ }^{29}$ Reinterpretation of the previously reported MALDI-ToF mass spectra of PHB and PMLA ${ }^{\text {Bn }}$, similarly synthesized by ROP of rac-BL and $\mathrm{MLA}^{\mathrm{Bn}}$, respectively, mediated by BEMP (ESI, Fig. S14 and $\mathrm{S} 15 \dagger),{ }^{22}$ further supports this suggested mechanism.

\section{$\mathrm{PBPL}^{\mathrm{OR}} \mathrm{S}$ recovered from the ROP of $r a c-\mathrm{BPL}^{\mathrm{OR}} \mathrm{S}$ mediated by TBD}

The typical ${ }^{1} \mathrm{H}, 2 \mathrm{D}$ and J-MOD NMR spectra of PBPL ${ }^{\mathrm{OR}} \mathrm{S}$ recovered from the ROP of rac-BPL ${ }^{\mathrm{OR}} \mathrm{S}$ mediated by TBD (Table 2) are exemplified in Fig. 5 with PBPL $^{\mathrm{OBn}}$ and in ESI, Fig. S16$\mathrm{S} 19, \dagger$ with $\mathrm{PBPL}^{\mathrm{OR}} \mathrm{S}$. All these NMR spectra unambiguously showed, alongside the characteristic backbone methine and methylene hydrogens' signals, the resonances of both crotonate and TBD moieties $\left(\delta_{1 \mathrm{H}} \mathrm{ppm} 3.28\left(\mathrm{CH}_{2}{ }_{2} \mathrm{~N}=\mathrm{C}(\mathrm{N}) \mathrm{NHCH}^{o}{ }_{2}\right)\right.$, $3.20\left(\mathrm{CH}_{2}^{l} \mathrm{~N}(\mathrm{C}) \mathrm{CH}_{2}{ }_{2}\right)$, and $\left.1.93\left(\mathrm{CH}_{2} \mathrm{CH}^{k, n}{ }_{2} \mathrm{CH}_{2}\right)\right)$. The 2D COSY NMR spectra evidenced, similarly as with BEMP, a correlation between the vinylic and methylene hydrogens of the crotonate end-group, supporting the crotonate chain-end (ESI, Fig. S18 and S19†).

Further information was gained from MALDI-ToF MS analyses of the isolated $\mathrm{PBPL}^{\mathrm{OR}}$ samples (Fig. 6). Two distinct populations of macromolecules were observed with a repeating unit of $192 \mathrm{~g} \mathrm{~mol}^{-1}$. A first population I corresponds to $\mathrm{PBPL}^{\mathrm{OBn}}$ flanked with a TBD- $N$-acyl- $\alpha, \beta$-unsaturated species and hydroxy chain-ends (Scheme 3, 6), as unequivocally confirmed by the isotopic simulation (e.g. $m / z_{\exp }=1659.753 \mathrm{~g} \mathrm{~mol}^{-1} v$. 


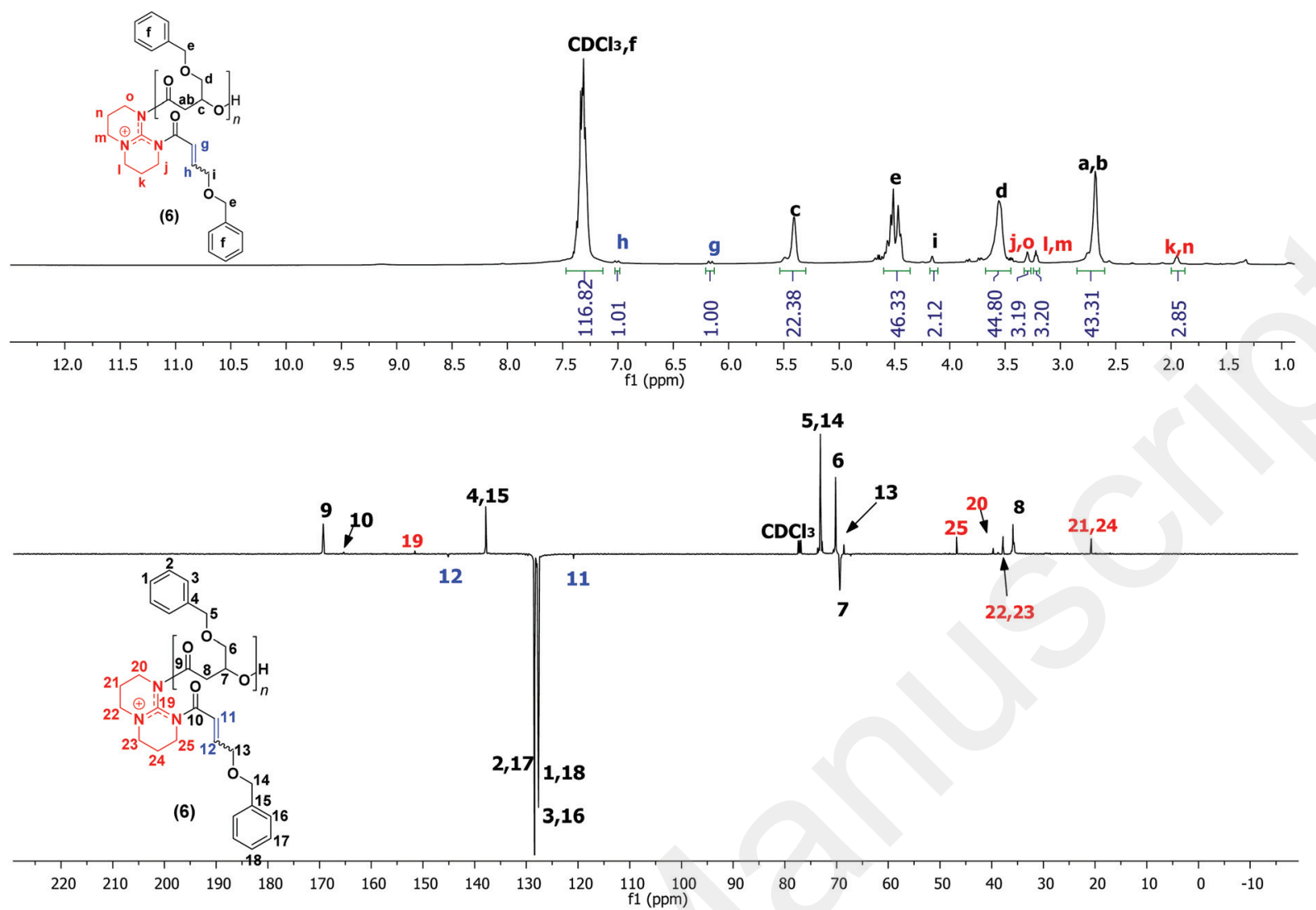

Fig. $5{ }^{1} \mathrm{H}\left(500 \mathrm{MHz}, \mathrm{CDCl}_{3}, 25^{\circ} \mathrm{C}\right.$ ) (top) and J-MOD (125 MHz, CDCl $3,25^{\circ} \mathrm{C}$ ) (bottom) NMR spectra of a purified PBPL ${ }^{\mathrm{OBn}}$ sample recovered from the ROP of rac-BPL ${ }^{\mathrm{OBn}}$ mediated by TBD (Table 2, entry 7), depicting only one (I, Scheme 3, 6) out of the two populations (I and II, Scheme 3, 6,8) observed by MALDI-ToF MS (Fig. 6).

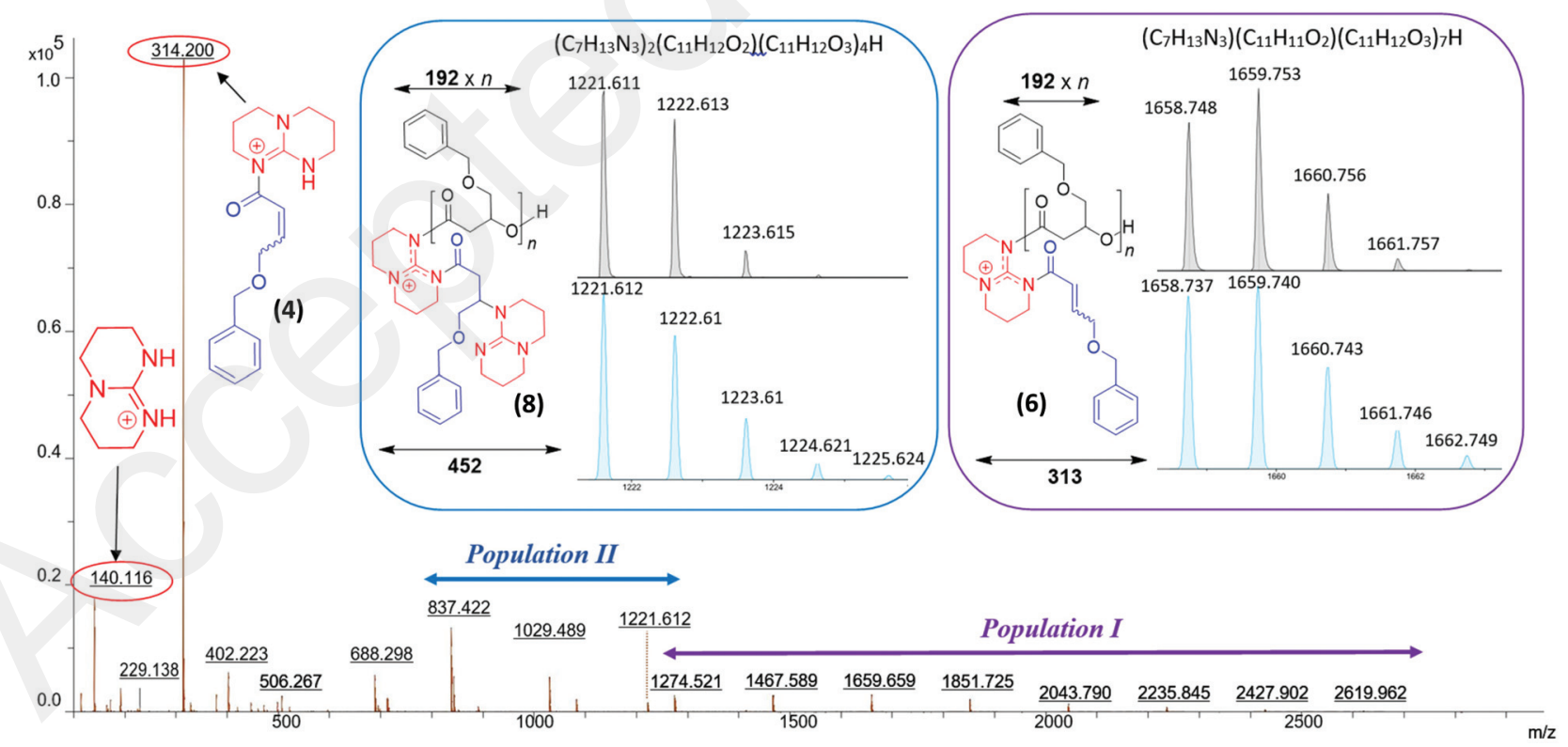

Fig. 6 MALDI-ToF mass spectrum (positive mode, DCTB matrix, $\mathrm{Na}^{+}$cationizing salt) of a sample freshly synthesized from the ROP of rac-BPL ${ }^{\mathrm{OBn}}$ mediated by TBD (Table 2, entry 6 ) showing populations corresponding to PBPL ${ }^{\mathrm{OBn}}$ macromolecules end-capped with both an $\alpha$-benzyloxycrotonateTBD and an $\omega$-hydroxy end-groups (population I; Scheme 3, 6), and to a subsequently modified population I where a TBD molecule is added onto the crotonate moiety to give population II (Scheme 3, 8); the zoomed regions correspond to the simulated (blue, bottom) and experimental (black, top) corresponding spectra, respectively. Species TBD : $\mathrm{BPL}^{\mathrm{OR}}$ (Scheme 3,4$)$ and $[\mathrm{TBDH}]^{+}$are also observed. 

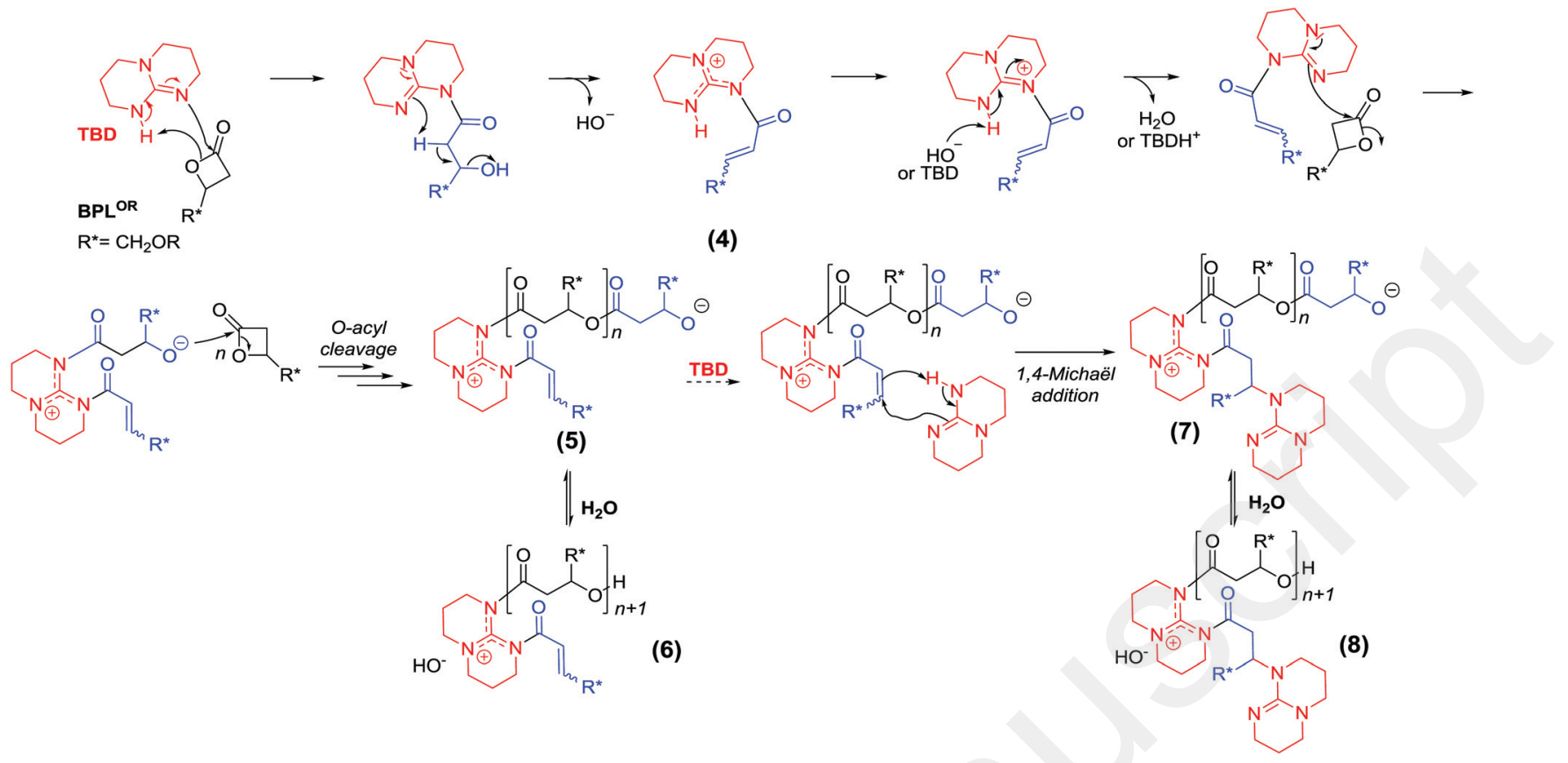

Scheme 3 Proposed mechanism for the ROP of rac-BPL ${ }^{O R}$ s mediated by TBD, proceeding via an $\mathrm{O}$-acyl cleavage of BPL ${ }^{\mathrm{OR}}$ into species 5 mediated by 4 , and/or the plausible side polymer species 7. Species 6 and 8 refer to the protonated form of 5 and 7 , respectively, showing the various (macro) molecular species (4-8).

$m / z_{\text {simul }}=1659.740 \mathrm{~g} \mathrm{~mol}{ }^{-1}$ for $n=7$; see right zoomed region (purple)). This TBD- $N$-acyl- $\alpha, \beta$-unsaturated species most likely originates from the 1:1 TBD:BPL ${ }^{\mathrm{OR}}$ adduct (Scheme 3,4) from which $\mathrm{H}_{2} \mathrm{O}$ or $[\mathrm{TBDH}]^{+}$is then eliminated. This is reminiscent of the mechanism initially suggested for the ROP of BL and $\mathrm{MLA}^{\mathrm{Bn}}$ mediated by this same guanidine. ${ }^{22}$ This adduct would propagate the polymerization via an $O$-acyl cleavage operated by the second nucleophilic nitrogen of TBD, generating a zwitterionic propagating species (Scheme 3, 5) ultimately giving population I (Fig. 6, Scheme 3, 6) after protonation. ${ }^{30 a}$ The second population II, issued from the former one, features an additional TBD moiety, as supported by the isotopic simulation with e.g. $m / z_{\exp }=1221.611 \mathrm{~g} \operatorname{mol}^{-1}$ vs. $m / z_{\text {simul }}=$ $1221.612 \mathrm{~g} \mathrm{~mol}^{-1}$ for $n=4$ (see left zoomed region (blue)). Most likely, the $\alpha, \beta$-unsaturation from 5 acts as a Michaël acceptor towards TBD, thereby generating macromolecules 7 which form population II (Fig. 6, Scheme 3, 8) upon protonation. ${ }^{30 b}$ From these two populations, $[\mathrm{TBDH}]^{+}\left(\mathrm{m} / \mathrm{z}_{\exp }=\right.$ $\left.140.116 \mathrm{~g} \mathrm{~mol}^{-1}\right)$ and TBD-crotonate ${ }^{+}\left(\mathrm{m} / \mathrm{z}_{\exp }=314.200 \mathrm{~g}\right.$ $\mathrm{mol}^{-1}$ ) species could be abstracted, as observed in the experimental mass spectrum (Fig. 6). From these results, it thus appears that TBD would be following a nucleophilic pathway to ring-open $\mathrm{BPL}^{\mathrm{OR}} \mathrm{s}$, rather than a basic one, as depicted in Scheme 3. This is reminiscent of the mechanism reported for the ROP of $\varepsilon$-caprolactone promoted by TBD under similar bulk operating conditions. ${ }^{31}$ Further support of this mechanism was gained from the re-interpretation of the previously reported MALDI-ToF mass spectra of PHB and PMLA ${ }^{\text {Bn }}$ similarly obtained by ROP of rac-BL and $\mathrm{MLA}^{\mathrm{Bn}}$ mediated by TBD (ESI, Fig. S20 and S22 $\uparrow$ ), in agreement with the corresponding
NMR spectra (Fig. S21 and S23†). ${ }^{22}$ On the other hand, this is in contrast with the TBD-mediated anionic ROP of BL reported recently by Coulembier and co-workers in which TBD is proposed to activate the $\beta$-lactone via its basic character. ${ }^{24}$

\section{$\mathrm{PBPL}^{\mathrm{OR}} \mathrm{S}$ recovered from the ROP of rac-BPL ${ }^{\mathrm{OR}} \mathrm{s}$ mediated by DBU}

Similarly to the $\mathrm{PBPL}^{\mathrm{OR}} \mathrm{S}$ synthesized using BEMP or TBD, $1 \mathrm{D}$ and $2 \mathrm{D}{ }^{1} \mathrm{H}$ NMR analyses of $\mathrm{PBPL}^{\mathrm{OR}} \mathrm{S}$ prepared from the alike ROP of rac-BPL ${ }^{\mathrm{OR}} \mathrm{S}$ mediated by DBU unambiguously evidenced the presence of both $\alpha, \beta$-unsaturation and DBU moieties $\left(\delta_{1_{\mathrm{H}}}\right.$ ppm $3.37\left(\mathrm{CH}_{2}^{j} \mathrm{~N}(\mathrm{C}) \mathrm{CH}_{2}^{k}\right), 3.34\left(\mathrm{CNCH}^{m}{ }_{2} \mathrm{CH}_{2}\right), 2.80\left(\mathrm{CH}_{2} \mathrm{CH}_{2}{ }_{2} \mathrm{C}\right.$ $(\mathrm{N})=\mathrm{N}), 1.93\left(\mathrm{NCH}_{2} \mathrm{CH}_{2} \mathrm{CH}_{2}\right), 1.70\left(\mathrm{CH}_{2} \mathrm{CH}_{2} \mathrm{CH}_{2}{ }_{2} \mathrm{CH}_{2}^{o} \mathrm{CH}_{2}\right)$, $1.61\left(\mathrm{CH}_{2} \mathrm{CH}_{2}^{q} \mathrm{CH}_{2} \mathrm{CH}_{2} \mathrm{CH}_{2}\right)$ (Fig. 7, top) for PBPL ${ }^{\mathrm{OBn}}$, and ESI, Fig. S24 and $\mathrm{S} 25 \dagger$ for other $\left.\mathrm{PBPL}^{\mathrm{OR}} \mathrm{S}\right)$. The corresponding carbon resonances and $2 \mathrm{D}$ correlations were identified in the J-MOD and COSY spectra, respectively (Fig. 7, bottom for $\mathrm{PBPL}^{\mathrm{OBn}}$, and ESI, Fig. S24-S27† for other $\left.\mathrm{PBPL}^{\mathrm{OR}} \mathrm{S}\right)$.

MALDI-ToF MS of the thus prepared $\mathrm{PBPL}^{\mathrm{OR}_{\mathrm{S}}}$ provided valuable information. Two macromolecular populations with a repeating unit of $192 \mathrm{~g} \mathrm{~mol}^{-1}$ are clearly observed in the mass spectrum of $\mathrm{PBPL}^{\mathrm{OBn}}$ (Fig. 8). The first population $\mathbf{I}$ is consistent with $\mathrm{PBPL}^{\mathrm{OBn}}$ chains end-capped with a $\beta$-hydroxyester and DBU moieties (e.g. $m / z_{\exp }=1113.526 \mathrm{~g} \mathrm{~mol}^{-1}$ vs. $m / z_{\text {simul }}=$ $1113.532 \mathrm{~g} \mathrm{~mol}^{-1}$ for $n=5$ ) in agreement with the simulated isotopic spectrum (see left zoomed region (blue)). The other population II features a benzyloxy-crotonate and a carboxylic acid chain-end-groups, matching the isotopic simulation, with e.g. $m / z_{\exp }=2328.869 \mathrm{~g} \mathrm{~mol}^{-1}$ vs. $m / z_{\text {simul }}=2328.936 \mathrm{~g} \mathrm{~mol}^{-1}$ for $n=11$ (see right zoomed region (purple)). 


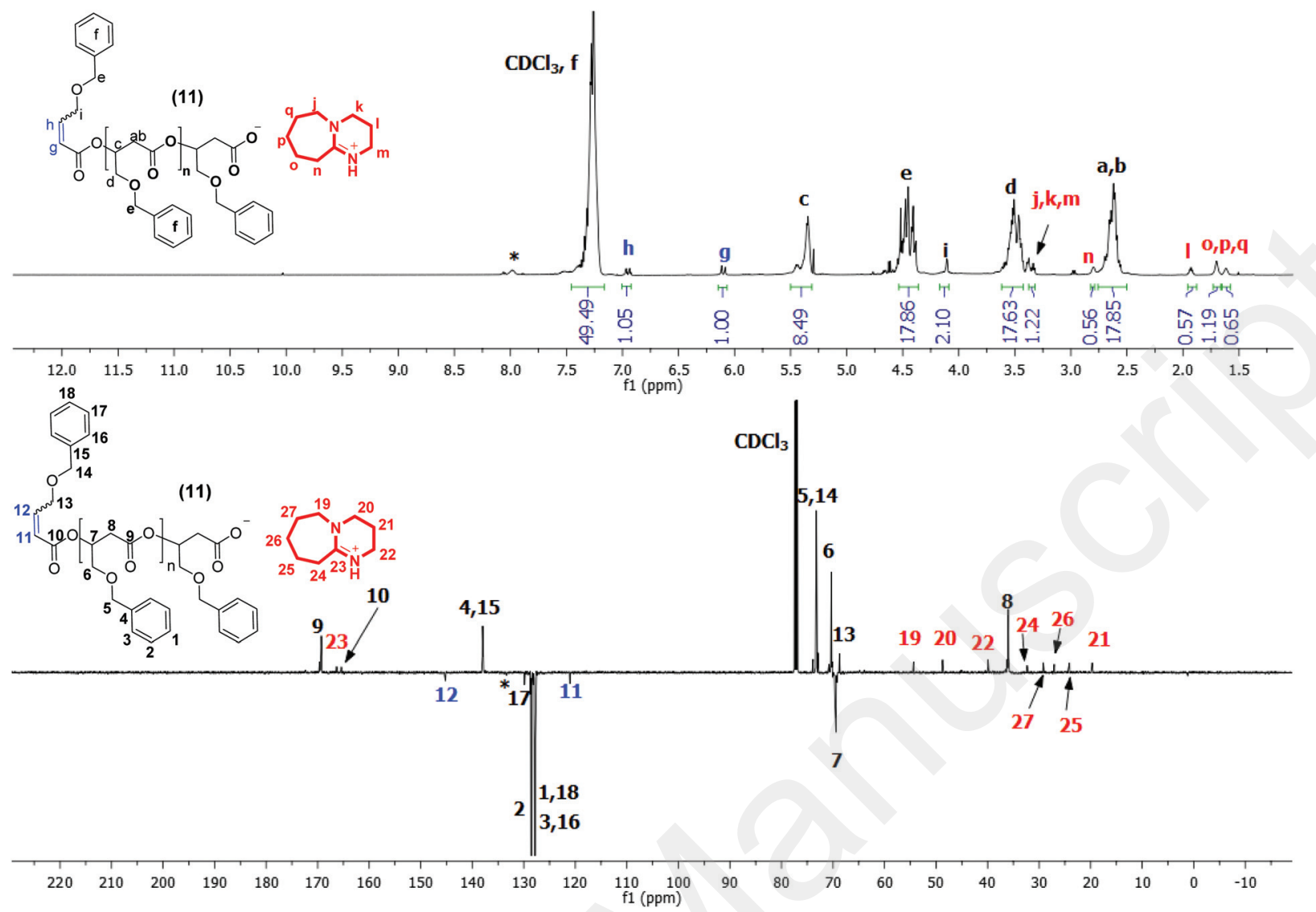

Fig. $7{ }^{1} \mathrm{H}\left(500 \mathrm{MHz}, \mathrm{CDCl}_{3}, 25^{\circ} \mathrm{C}\right)$ (top) and J-MOD $\left(125 \mathrm{MHz}, \mathrm{CDCl}_{3}, 25^{\circ} \mathrm{C}\right)$ (bottom) NMR spectra of PBPL ${ }^{\mathrm{OBn}}$ recovered from the ROP of rac$\mathrm{BPL}^{\mathrm{OBn}}$ mediated by DBU (Table 3, entry 3), depicting only one species (Scheme 4, 11) out of the two (Scheme 4, 9,11) (*: unidentified impurity).

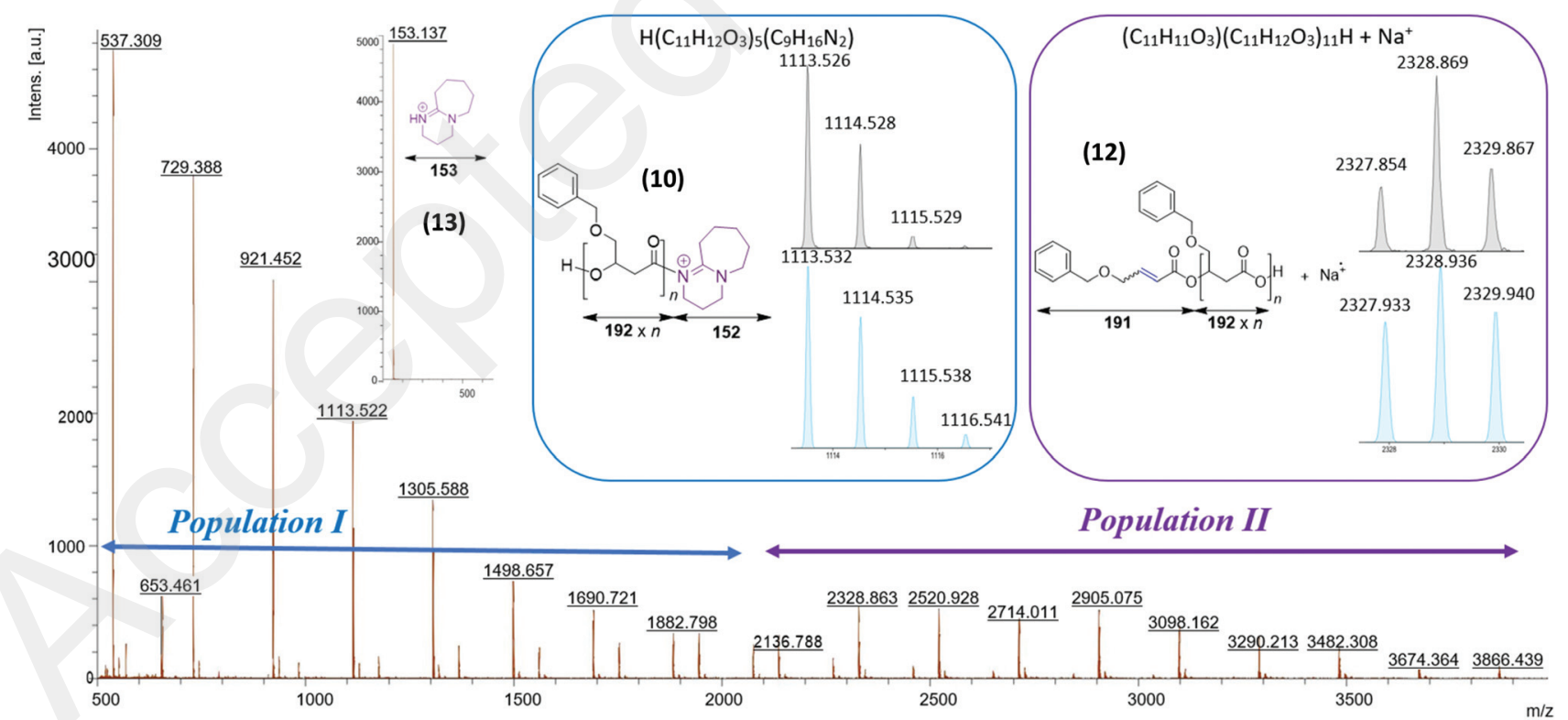

Fig. 8 MALDI-ToF mass spectrum (positive mode, DCTB matrix, $\mathrm{Na}^{+}$cationizing agent) of a sample freshly synthesized from the ROP of rac-BPL ${ }^{\mathrm{OBn}}$ mediated by DBU (Table 3, entry 3) showing populations corresponding to PBPL ${ }^{\mathrm{OBn}}$ macromolecules end-capped with both an $\alpha$-hydroxy and $\omega-\mathrm{DBU}^{+}$groups (population I, Scheme 4,10), to $\mathrm{PBPL}^{\mathrm{OBn}}$ macromolecules ionized with $\mathrm{Na}^{+}$and end-capped with both an $\alpha$-crotonate and $\omega$-carboxylic acid (population II, Scheme 4, 12), and to $\mathrm{DBUH}^{+}$(Scheme 4, 13); the zoomed regions correspond to the simulated (blue, bottom) and experimental (black, top) spectra, respectively. Refer to ESI, Fig. S28 † for the MALDI-ToF mass spectrum of same sample analyzed in the absence of a cationizing agent, showing only population I. 

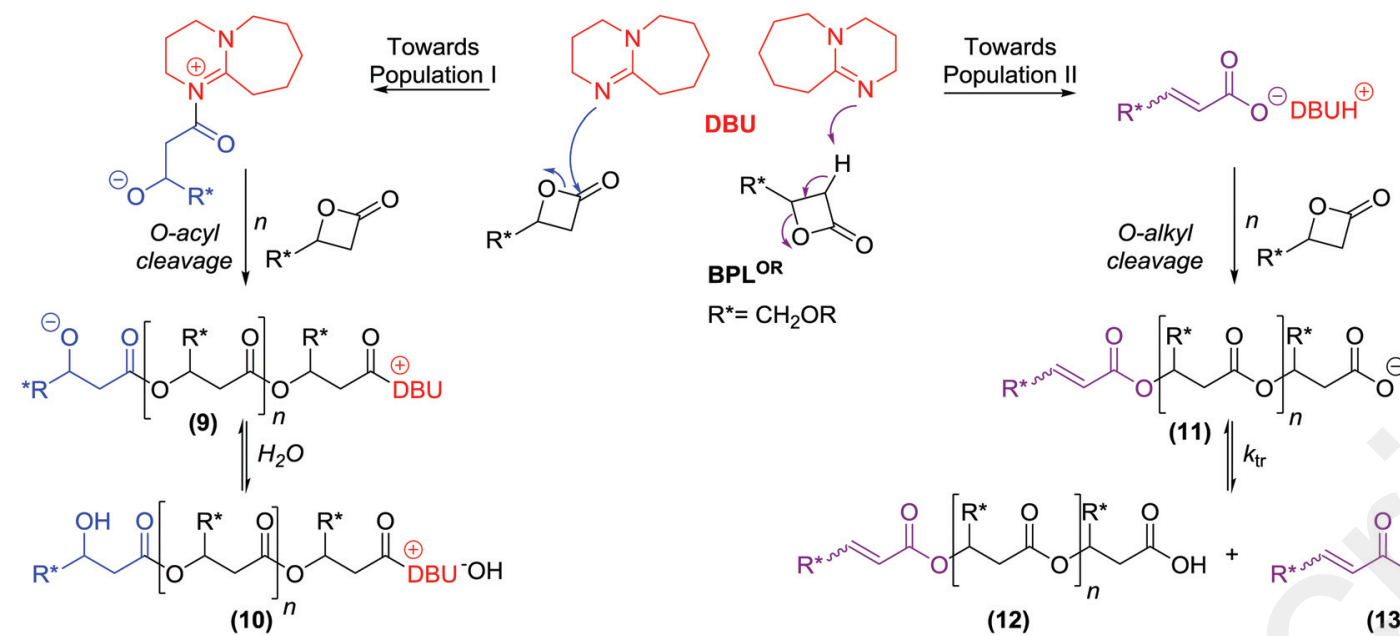

$\mathrm{R}^{*}=\mathrm{CH}_{2} \mathrm{OR}$

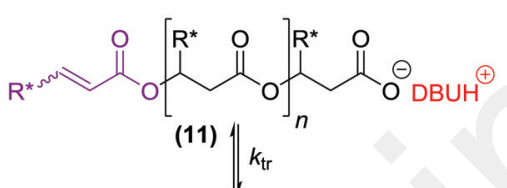

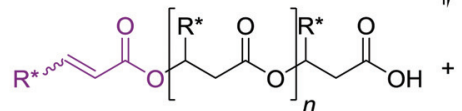

(12)

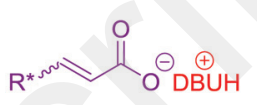

(13)

Scheme 4 Proposed mechanism for the ROP of rac-BPL ${ }^{\mathrm{OR}}$ mediated by the dual organocatalyst DBU proceeding either via an $\mathrm{O}$-acyl cleavage when acting as a nucleophile (blue pathway; 9), or via an O-alkyl cleavage when behaving as a base (purple pathway; 11). Populations I and II observed in the MALDI-ToF mass spectra (Fig. 8) refer to the macromolecular species 10 and 12 obtained upon protonation and transfer reactions, respectively.

The identification of such end-capping groups suggests that DBU behaves as a dual catalyst, both basic and nucleophilic. It would thus mediate the ROP of $r a c-\mathrm{BPL}^{\mathrm{OR}} \mathrm{S}$ through two competitive mechanistic pathways, in association with the acidic $\alpha-\mathrm{H}$ and electrophilic $\mathrm{C}=\mathrm{O}$ reactivity of $\mathrm{BPL}^{\mathrm{OR}}$ monomers. Hence, similarly to BEMP, DBU would act as a basic catalyst to form in situ the $\alpha, \beta$-unsaturated carboxylate-DBU real active species which propagates via $O$-alkyl cleavage of the $\beta$-lactone to ultimately generate macromolecules of population II (Fig. 8, Scheme 4, 12). In addition, similarly to TBD, DBU can promote the nucleophilic $\mathrm{ROP}$ of $r a c-\mathrm{BPL}^{\mathrm{OR}} \mathrm{S}$ via its $\mathrm{O}$-acyl cleavage, generating an alkoxy propagating species to eventually form $\mathrm{PBPL}^{\mathrm{OBn}}$ corresponding to population I (Fig. 8, Scheme 4, 10). This latter approach was previously reported for the bulk ROP of lactide using DBU only ${ }^{32}$ or upon using other amine functional organocatalysis. ${ }^{33}$ Further evidence of the DBU's dual activity and of the proposed mechanism was gained from the reinterpretation of the previously reported MALDI-ToF mass spectra of samples recovered from the ROP of MLA $^{\text {Bn }}$ mediated by DBU (ESI, Fig. S29†). ${ }^{22 b}$

\section{Conclusion}

Functional PHAs, namely $\mathrm{PBPL}^{\mathrm{OR}} \mathrm{s}$, have been successfully synthesized from the bulk ROP of rac-BPL ${ }^{\mathrm{OR}}$ monomers at $60{ }^{\circ} \mathrm{C}$ using exclusively BEMP, TBD, or DBU as organocatalyst. The activity of these organocatalysts, under these operating conditions, is modest as typically encountered with four-membered ring $\beta$-lactones when compared to larger ones $(\geq$ six-membered ring lactones). Their activity towards $\mathrm{BPL}^{\mathrm{OR}} \mathrm{S}$ is lower than in the alike ROP of the related $\mathrm{BL}$ and $\mathrm{MLA}^{\mathrm{Bn}} \beta$-lactones; we assume this may be due to the $\mathrm{CH}_{2} \mathrm{OR}$ ether substituent which makes the monomer less electrophilic as compared to the methyl or benzyloxycarbonyl function of BL and $\mathrm{MLA}^{\mathrm{Bn}}$, respectively.
Inherent to their own intrinsic chemical features, each of the organocatalysts supports a unique mechanistic pathway, as suggested by combined NMR and MALDI-ToF MS detailed analyses of the $\mathrm{PBPL}^{\mathrm{OR}} \mathrm{S}$. ROP mechanisms at play dictate the nature of the macromolecules' chain-end-groups. BEMP, the most basic and bulky organocatalyst, generates upon proton abstraction and $O$-alkyl cleavage of the $\mathrm{BPL}^{\mathrm{OR}}$ monomer, a [carboxylate $]^{-} /[\mathrm{BEMPH}]^{+}$initiator which propagates the reaction, most likely accompanied by some transfer reactions. BEMP thus appears to behave as a base, similarly to tert-butoxide salts that initiate the ROP of BL via proton transfer in an irreversible manner. ${ }^{29 e}$ On the contrary, the highly nucleophilic TBD forms, via $O$-acyl cleavage of $\mathrm{BPL}^{\mathrm{OR}}$, a $1: 1 \mathrm{~N}$-acyl- $\alpha, \beta$-unsaturated adduct, that subsequently propagates in the same manner. Finally, the observed dual basic and nucleophilic activity of DBU is comparable to that of the previously reported strong base initiators such as $\mathrm{ROK},{ }^{34}$ favoring the scission of both $O$-acyl and $O$-alkyl bonds of the $\mathrm{BPL}^{\mathrm{OR}}$ monomer, eventually forming alkoxy and carboxylate active species, respectively. Apparently, DBU's dual activity prevails once again in the polymerization. The mechanisms proposed herein for the organocatalyzed ROP of $\mathrm{BPL}^{\mathrm{OR}} \mathrm{S}$ mediated by BEMP, TBD or DBU, are fully compatible with those of the alike ROP of BL and $\mathrm{MLA}^{\mathrm{Bn}}$, respectively (ESI, Fig. S14, S15, S20, S23 and S29†). ${ }^{22}$ These results highlight that the mechanism operating in an organocatalyzed ROP of a $\beta$-lactone is thus highly dependent on both the chemical nature of the functionality of the monomer's substituent and on the chemical specificity of the organocatalysts used. We assume it may also be strongly affected by the operating conditions used to synthesize the polymers, in particular if the reactions are conducted neat or in solution. We suspect that the latter modus operandi parameter might account for the differences observed between Coulembier's work and our studies (refer to the $\mathrm{ESI}^{\dagger}$ ). ${ }^{24}$ 


\section{Conflicts of interest}

There are no conflicts to declare.

\section{Acknowledgements}

This research was financially supported in part by the Lebanese University and Université de Rennes 1 (Ph.D. grant to R.S.). We are grateful to UMS ScanMAT and especially to Clément Orione and Elsa Caytan, for extensive MS and NMR analyses, respectively.

\section{References}

1 (a) J. Lu, R. C. Tappel and C. T. Nomura, Polym. Rev., 2009, 49, 226-248; (b) S. Taguchi, T. Iwata, H. Abe and Y. Doi, Polymer Science: A Comprehensive Reference, 2012, vol. 9, pp. 157-182.

2 M. Lemoigne, CR Acad. Sci., 1925, 180, 1539-1541.

3 (a) R. W. Lenz and R. H. Marchessault, Biomacromolecules, 2005, 6, 1-8; (b) H. M. Müller and D. Seebach, Angew. Chem., Int. Ed. Engl., 1993, 32, 477-502.

4 (a) B. Laycock, P. Halley, S. Pratt, A. Werker and P. Lant, Prog. Polym. Sci., 2013, 38, 536-583; (b) K. Sudesh, H. Abe and Y. Doi, Prog. Polym. Sci., 2000, 25, 1503-1555.

5 P. Dubois, O. Coulembier and J.-M. Raquez, Handbook of Ring-Opening Polymerization, Wiley-VCH, Weinheim, 2009, pp. 227-254.

6 (a) H. R. Kricheldorf and N. Scharnagl, J. Macromol. Sci., Chem., 1989, 26, 951-968; (b) A. Duda, J. Polym. Sci., Part A: Polym. Chem., 1992, 30, 21-29; (c) A. Hofman, S. Słomkowski and S. Penczek, Makromol. Chem., 1984, 185, 91-101.

7 For leading reviews on metal-catalyzed ROP of cyclic esters, see: (a) J. F. Carpentier, Macromol. Rapid Commun., 2010, 31, 1696-1705; (b) C. M. Thomas, Chem. Soc. Rev., 2010, 39, 165-173; (c) M. J. Stanford and A. P. Dove, Chem. Soc. Rev., 2010, 39, 486-494; (d) P. J. Dijkstra, H. Du and J. Feijen, Polym. Chem., 2011, 2, 520-527; (e) S. Dutta, W.-C. Hung, B.-H. Huang and C.-C. Lin, Synth. Biodegrad. Polym., 2011, 245, 219-283; $(f)$ A. Buchard, C. M. Bakewell, J. Weiner and C. K. Williams, Top. Organomet. Chem., 2012, 39, 175-224; (g) A. Sauer, A. Kapelski, C. Fliedel, S. Dagorne, M. Kol and J. Okuda, Dalton Trans., 2013, 42, 9007-9023; (h) S. M. Guillaume, E. Kirillov, Y. Sarazin and J.-F. Carpentier, Chem. - Eur. J., 2015, 21, 7988-8003; (i) J.-F. Carpentier, Organometallics, 2015, 34, 4175-4189; (j) H. Li, R. Shakahroun, S. M. Guillaume and J.-F. Carpentier, Chem. - Eur. J., 2020, 26, 128-138.

8 N. Ajellal, C. M. Thomas and J.-F. Carpentier, J. Polym. Sci., Part A: Polym. Chem., 2009, 47, 3177-3189.

9 (a) C. G. Jaffredo, Y. Chapurina, S. M. Guillaume and J. F. Carpentier, Angew. Chem., Int. Ed., 2014, 53, 26872691; (b) C. G. Jaffredo, Y. Chapurina, E. Kirillov,
J.-F. Carpentier and S. M. Guillaume, Chem. - Eur. J., 2016, 22, 7629-7641.

10 (a) R. Ligny, M. M. Hänninen, S. M. Guillaume and J.-F. Carpentier, Angew. Chem., Int. Ed., 2017, 56, 1038810393; (b) R. Ligny, M. M. Hänninen, S. M. Guillaume and J.-F. Carpentier, Chem. Commun., 2018, 54, 8024-8031; (c) R. Ligny, S. M. Guillaume and J. F. Carpentier, Chem. Eur. J., 2019, 25, 6412-6424.

11 (a) X. Tang and E. Y.-X. Chen, Nat. Commun., 2018, 9, 2345; (b) X. Tang, A. H. Westlie, E. M. Watson and E. Y.-X. Chen, Science, 2019, 366, 754-758.

12 (a) G. Barouti, K. Jarnouen, S. Cammas-Marion, P. Loyer and S. M. Guillaume, Polym. Chem., 2015, 6, 5414-5429; (b) G. Barouti, A. Khalil, C. Orione, K. Jarnouen, S. Cammas-Marion, P. Loyer and S. M. Guillaume, Chem. Eur. J., 2016, 22, 2819-2830.

13 For leading reviews on organocatalyzed ROP of cyclic esters, see: (a) A. Dove, H. Sardon and S. Naumann, Organic Catalysis for Polymerisation, Royal Society of Chemistry, 2018; (b) A. Bossion, K. V. Heifferon, L. Meabe, N. Zivic, D. Taton, J. L. Hedrick, T. E. Long and H. Sardon, Prog. Polym. Sci., 2019, 90, 164-210; (c) W. N. Ottou, H. Sardon, D. Mecerreyes, J. Vignolle and D. Taton, Prog. Polym. Sci., 2016, 56, 64-115; (d) M. K. Kiesewetter, E. J. Shin, J. L. Hedrick and R. M. Waymouth, Macromolecules, 2010, 43, 2093-2107.

14 (a) B. G. G. Lohmeijer, R. C. Pratt, F. Leibfarth, J. W. Logan, D. A. Long, A. P. Dove, F. Nederberg, J. Choi, C. Wade, R. M. Waymouth and J. L. Hedrick, Macromolecules, 2006, 39, 8574-8583; (b) L. Zhang, F. Nederberg, R. C. Pratt, R. M. Waymouth, J. L. Hedrick and C. G. Wade, Macromolecules, 2007, 40, 4154-4158.

15 A. Khalil, S. Cammas-Marion and O. Coulembier, J. Polym. Sci., Part A: Polym. Chem., 2019, 57, 657-672.

16 R. Schwesinger, J. Willaredt, H. Schlemper, M. Keller, D. Schmitt and H. Fritz, Chem. Ber., 1994, 127, 2435-2454.

17 (a) Y.-J. Lee, J. Lee, M.-J. Kim, B.-S. Jeong, J.-H. Lee, T.-S. Kim, J. Lee, J.-M. Ku, S.-S. Jew and H.-G. Park, Org. Lett., 2005, 7, 3207-3209; (b) J. Lee, Y.-I. Lee, M. J. Kang, Y.-J. Lee, B.-S. Jeong, J.-H. Lee, M.-J. Kim, J.-Y. Choi, J.-M. Ku and H.-G. Park, J. Org. Chem., 2005, 70, 4158-4161. 18 (a) D. Simoni, M. Rossi, R. Rondanin, A. Mazzali, R. Baruchello, C. Malagutti, M. Roberti and F. P. Invidiata, Org. Lett., 2000, 2, 3765-3768; (b) P. Hammar, C. Ghobril, C. Antheaume, A. Wagner, R. Baati and F. Himo, J. Org. Chem., 2010, 75, 4728-4736; (c) R. Pierre, F. Gaigne, G. ElBazbouz, G. Mouis, G. Ouvry, L. Tomas and C. S. Harris, Synlett, 2018, 29, 1102-1106.

19 (a) H. Oediger and F. Möller, Angew. Chem., Int. Ed., 1967, 6, 76; (b) H. Oediger, F. Moeller and K. Eiter, Synthesis, 1972, 591-598.

20 (a) X. Liu, S. Zhang, Q.-W. Song, X.-F. Liu, R. Ma and L.-N. He, Green Chem., 2016, 18, 2871-2876; (b) J. Sun, W. Cheng, Z. Yang, J. Wang, T. Xu, J. Xin and S. Zhang, Green Chem., 2014, 16, 3071-3078; (c) J. E. Taylor, S. D. Bull and J. M. Williams, Chem. Soc. Rev., 2012, 41, 2109-2121; 
(d) R. Reed, R. Réau, F. Dahan and G. Bertrand, Angew. Chem., Int. Ed. Engl., 1993, 32, 399-401.

21 (a) C.-L. Zhang, Z.-F. Zhang, Z.-H. Xia, Y.-F. Han and S. Ye, J. Org. Chem., 2018, 83, 12507-12513; (b) A. K. Morri, Y. Thummala and V. R. Doddi, Org. Lett., 2015, 17, 46404643; (c) R. Singh, D. S. Raghuvanshi and K. N. Singh, Org. Lett., 2013, 15, 4202-4205; (d) Y. Thummala, G. V. Karunakar and V. R. Doddi, Adv. Synth. Catal., 2019, 361, 611-616.

22 (a) C. G. Jaffredo, J.-F. Carpentier and S. M. Guillaume, Macromol. Rapid Commun., 2012, 33, 1938-1944; (b) C. G. Jaffredo, J.-F. Carpentier and S. M. Guillaume, Polym. Chem., 2013, 4, 3837-3850.

23 C. G. Jaffredo, J.-F. Carpentier and S. M. Guillaume, Macromolecules, 2013, 46, 6765-6776.

24 S. Moins, C. Henoumont, J. De Winter, A. Khalil, S. Laurent, S. Cammas-Marion and O. Coulembier, Polym. Chem., 2018, 9, 1840-1847.

25 J. A. Schmidt, E. B. Lobkovsky and G. W. Coates, J. Am. Chem. Soc., 2005, 127, 11426-11435.

26 A preliminary set of experiments on the ROP of $\mathrm{BPL}^{\mathrm{OBn}}$ mediated by BEMP in solution in an NMR tube $\left(\mathrm{C}_{6} \mathrm{D}_{6}\right.$, $\left[\mathrm{BPL}^{\mathrm{OBn}}\right]_{0}=0.38 \mathrm{~mol} \mathrm{~L}^{-1}$ ) showed that the polymerization remained ineffective over $4 \mathrm{~h}$ at $60{ }^{\circ} \mathrm{C}$ (Conv. BPLOBn $<5 \%$ ), as monitored by ${ }^{1} \mathrm{H}$ NMR spectroscopy.

27 Note that the MALDI-ToF mass spectra previously recorded for $\mathrm{PHB}$ and $\mathrm{PMLA}^{\mathrm{Bn}}$ samples prepared form the alike BEMP mediated ROP of BL and $\mathrm{MLA}^{\mathrm{Bn}}$, respectively, could not evidence, the possible presence of - $\mathrm{COOH}$ end-capping group because the matrix/cationizing agent used did not enable it. $^{22} \mathrm{~A}$ revised analysis of these MALDI-ToF mass spectra is presented in the ESI (ESI, Fig. S14 and S15 $\dagger$ ) and shows that the ROP of BL and MLA $^{\mathrm{Bn}}$ mediated by BEMP proceeds in the same way as the ROP of $r a c-\mathrm{BPL}^{\mathrm{OR}} \mathrm{S}$.
28 (a) Z. Jedliński, P. Kurcok, M. Kowalczuk and J. Kasperczyk, Die Makromolekulare Chemie, 1986, 187, 1651-1656; (b) O. Coulembier, P. Degée, S. Cammas-Marion, P. Guérin and P. Dubois, Macromolecules, 2002, 35, 9896-9903; (c) G. Y. Adamus and M. Kowalczuk, Biomacromolecules, 2008, 9, 696-703; (d) B. Raeskinet, S. B. Moins, L. Harvey, J. De Winter, C. l. Henoumont, S. Laurent and O. Coulembier, Macromolecules, 2019, 52, 6382-6392.

29 (a) Y. Zhang, R. A. Gross and R. W. Lenz, Macromolecules, 1990, 23, 3206-3212; (b) Z. Grobelny, M. Matlengiewicz, K. Skrzeczyna, A. Swinarew, S. Golba, J. Jurek-Suliga, M. Michalak and B. Swinarew, Int. J. Polym. Anal. Charact., 2015, 20, 457-468; (c) C. Mabille, M. Masure, P. Hémery and P. Guérin, Polym. Bull., 1998, 40, 381-387; (d) O. Coulembier, P. Degée, J. L. Hedrick and P. Dubois, Prog. Polym. Sci., 2006, 31, 723-747; (e) S. Penczek, M. Cypryk, A. Duda, P. Kubisa and S. Słomkowski, Prog. Polym. Sci., 2007, 32, 247-282.

30 (a) S. Kafka, B. Larissegger-Schnell and T. Kappe, J. Heterocycl. Chem., 2004, 41, 717-721; (b) A. Ying, Z. Li, J. Yang, S. Liu, S. Xu, H. Yan and C. Wu, J. Org. Chem., 2014, 79, 6510-6516.

31 (a) R. C. Pratt, B. G. G. Lohmeijer, D. A. Long, R. M. Waymouth and J. L. Hedrick, J. Am. Chem. Soc., 2006, 128, 4556-4557; (b) C. Sabot, K. A. Kumar, S. Meunier and C. Mioskowski, Tetrahedron Lett., 2007, 48, 38633866.

32 H. A. Brown, A. G. De Crisci, J. L. Hedrick and R. M. Waymouth, ACS Macro Lett., 2012, 1, 1113-1115.

33 (a) V. Katiyar and H. Nanavati, Polym. Chem., 2010, 1, 14911500; (b) H. R. Kricheldorf, N. Lomadze and G. Schwarz, Macromolecules, 2008, 41, 7812-7816.

34 Z. Grobelny, S. Golba and J. Jurek-Suliga, Polym. Bull., 2019, 76, 4951-4966. 